\title{
Age-Dependent Alterations of Corticostriatal Activity in the YAC128 Mouse Model of Huntington Disease
}

\author{
Prasad R. Joshi, ${ }^{1 \star}$ Nan-Ping Wu, ${ }^{1 \star}$ Véronique M. André, ${ }^{1}$ Damian M. Cummings, ${ }^{1}$ Carlos Cepeda, ${ }^{1}$ John A. Joyce, ${ }^{5}$ \\ Jeffrey B. Carroll, ${ }^{3,4}$ Blair R. Leavitt, ${ }^{3}$ Michael R. Hayden, ${ }^{3}$ Michael S. Levine, ${ }^{1}$ and Nigel S. Bamford ${ }^{2,5,6,7,8 *}$ \\ ${ }^{1}$ Mental Retardation Research Center, The David Geffen School of Medicine, University of California at Los Angeles, Los Angeles, California 90095, ${ }^{2}$ Center \\ on Human Development and Disability, University of Washington, Seattle, Washington 98105, ${ }^{3}$ Centre for Molecular Medicine and Therapeutics, Child and \\ Family Research Institute, Department of Medical Genetics and ${ }^{4}$ Department of Neuroscience, University of British Columbia, Vancouver, British \\ Columbia, Canada V5Z 4H4, and Departments of ${ }^{5}$ Neurology, ${ }^{6}$ Pediatrics, ${ }^{7}$ Psychology, and ${ }^{8}$ Neurobiology and Behavior, University of Washington and \\ Seattle Children's Hospital, Seattle, Washington 98105
}

Huntington disease is a genetic neurodegenerative disorder that produces motor, neuropsychiatric, and cognitive deficits and is caused by an abnormal expansion of the CAG tract in the huntingtin (htt) gene. In humans, mutated htt induces a preferential loss of medium spiny neurons in the striatum and, to a lesser extent, a loss of cortical neurons as the disease progresses. The mechanisms causing these degenerative changes remain unclear, but they may involve synaptic dysregulation. We examined the activity of the corticostriatal pathway using a combination of electrophysiological and optical imaging approaches in brain slices and acutely dissociated neurons from the YAC128 mouse model of Huntington disease. The results demonstrated biphasic age-dependent changes in corticostriatal function. At 1 month, before the behavioral phenotype develops, synaptic currents and glutamate release were increased. At 7 and 12 months, after the development of the behavioral phenotype, evoked synaptic currents were reduced. Glutamate release was decreased by 7 months and was markedly reduced by 12 months. These age-dependent alterations in corticostriatal activity were paralleled by a decrease in dopamine $\mathrm{D}_{2}$ receptor modulation of the presynaptic terminal. Together, these findings point to dynamic alterations at the corticostriatal pathway and emphasize that therapies directed toward preventing or alleviating symptoms need to be specifically designed depending on the stage of disease progression.

Key words: Huntington; striatum; cortex; excitability; glutamate; AMPA receptor; dopamine; dopamine receptor; neurotoxicity; corticostriatal; excitotoxicity

\section{Introduction}

Huntington disease (HD) is a severe autosomal dominant disorder that is produced by a polyglutamine expansion in the gene product huntingtin (htt) (Huntington's Disease Collaborative Research Group, 1993). HD is characterized by progressive neurodegeneration within the cortex and striatum, neuropsychiatric changes, progressive motor disturbances, and early death (Vonsattel and DiFiglia, 1998; Sapp et al., 1999). Although the progression of symptoms in HD have been classically attributed to cellular neurodegeneration (Young, 2003), mutant htt promotes

\footnotetext{
Received Nov. 28, 2008; revised Jan. 6, 2009; accepted Jan. 23, 2009.

This work was supported by National Institute of Neurological Disorders and Stroke (NINDS) Grant NS41574 (M.S.L.), The High Q Foundation (M.S.L.), Child's Health and Development Institute (M.S.L., M.R.H.), Canadian Institutes of Health Research Grant MOP 84438 (M.R.H.), the Huntington's Disease Society of America (M.R.H.), and by National Institute of Neurological Disorders and Stroke Grants NS052536 and NS060803, National Institute of Child Health and Human Development Grant HD02274, the University of Washington Royalty Research Award, Child Neurology Society, Vision Research Center at the University of Washington, and Children's Hospital and Regional Medical Center (Seattle, WA) (N.S.B.). We thank David Sulzer, Hui Zhang, Manjula Rao, Janet Lowe, Edwin W. Rubel, Elizabeth J. Slow, Donna Crandall, Gowry Fernando, Steven Gee, Lisa H. Zimberg, and lan J. Bamford.

*P.R.J., N.-P.W., and N.S.B. contributed equally to this work.

Correspondence should be addressed to Dr. Nigel S. Bamford, University of Washington, Department of Neurology, Box 356465, RR650, 1955 NE Pacific Street, Seattle, WA 98105. E-mail: bamford@u.washington.edu. D0I:10.1523/JNEUROSC1.5687-08.2009

Copyright $\odot 2009$ Society for Neuroscience $\quad$ 0270-6474/09/292414-14\$15.00/0
}

abnormal corticostriatal synaptic transmission (Li et al., 2003a,b; Smith et al., 2005) that may ultimately play a significant role in the development of clinical symptoms (Cepeda et al., 2007).

Recent studies have provided evidence for abnormal corticostriatal function in mouse models of HD (Mangiarini et al., 1996; Levine et al., 1999; Laforet et al., 2001; Cepeda et al., 2003; Li et al., 2004; Milnerwood and Raymond, 2007). Pathological alterations in cortical neurons (Turmaine et al., 2000; Klapstein et al., 2001; Laforet et al., 2001) significantly influence neuronal firing patterns, and subsequent changes in glutamatergic neurotransmission (Calabresi et al., 1995; Mainen and Sejnowski, 1996) may expose striatal medium spiny neurons (MSNs) to excessive excitation (Levine et al., 1999; Laforet et al., 2001; Cepeda et al., 2003).

Here, we combined electrophysiological and newly developed optical approaches to identify age-related changes along the corticostriatal pathway in YAC128 mice. The YAC128 mouse model of HD was created using a yeast artificial chromosome (YAC) containing the entire human HD gene with 128 CAG repeats, including all known promoter regions (Slow et al., 2003). The phenotype in YAC128 mice is protracted and progressive with impaired learning at 2 months, the onset of motor hyperactivity at 3 months, and bradykinesia with striatal neurodegeneration 
beginning at 7 months (Slow et al., 2003; Van Raamsdonk et al., 2005).

To evaluate age-dependent changes in corticostriatal activity, we used several groups of YAC128 transgenic mice, defined according to the development of symptoms: a young group (1 month) showing no evidence of abnormal behaviors and a middle-aged group (7 months), corresponding with the well established motor impairment. An older group of mice (12 months), displaying robust locomotor hypokinesis and well recognized neuropathological changes (Slow et al., 2003), was used to follow the progression of presynaptic changes. We examined synaptic currents evoked by activation of inputs from the motor cortex to MSNs in slices and used an acute isolation procedure to assess alterations in AMPA receptor (AMPAR) function. Optical methods measured glutamate release from motor cortical projections to the striatum and dopamine regulation of corticostriatal transmitter release.

The results demonstrated that age-dependent changes in corticostriatal activity are biphasic. At 1 month, synaptic responses, postsynaptic currents, and glutamate release were increased. At 7 and 12 months, synaptic responses and postsynaptic currents were reduced. Glutamate release began to decrease before 7 months and was markedly reduced by 12 months. These age-dependent alterations in corticostriatal activity were paralleled by a reduction in dopamine $\mathrm{D}_{2}$ modulation at the presynaptic terminal.

\section{Materials and Methods}

Animals. Mice were obtained from the University of British Columbia or from the breeding colony at University of California at Los Angeles (UCLA). This colony at UCLA was originally derived from the breeding colony at the University of British Columbia. Genotype was determined at or just before weaning and confirmed after the animals were killed. For electrophysiological experiments, YAC128 $(n=33)$ and littermate nontransgenic wild-type (WT) mice $(n=28)$ were examined at 1 month (10 YAC128 and 9 WT) before overt behavioral symptoms begin, at 7 months (18 YAC128 and 16 WT) after many of the symptoms have developed, and at 12 months (five YAC128 and three WT) after development of the full phenotype (Slow et al., 2003; Benn et al., 2007). For optical recordings and examination of glutamate release, YAC128 $(n=$ $18)$ and WT $(n=19)$ mice were examined at 1 month (eight YAC128 and eight WT), at 7 months (five YAC128 and six WT), and at 12 months (five YAC128 and five WT). All procedures were performed in accordance with the United States Public Health Service Guide for Care and Use of Laboratory Animals and were approved by the Institutional Animal Care and Use Committees at UCLA and the University of Washington.

Brain slices for electrophysiology. Procedures for killing mice and making slices have been described previously (Cepeda et al., 1998). Briefly, mice were anesthetized with halothane and decapitated. Brains were dissected and sliced in the coronal plane ( $350 \mu \mathrm{m}$ thick) in oxygenated ice-cold low- $\mathrm{Ca}^{2+}$ artificial CSF (ACSF) containing the following (in $\mathrm{mm}$ ): $130 \mathrm{NaCl}, 1.25 \mathrm{NaH}_{2} \mathrm{PO}_{4}, 26 \mathrm{NaHCO}_{3}, 5 \mathrm{MgCl}_{2}, 1 \mathrm{CaCl}_{2}$, and 10 glucose. After cutting, slices were incubated in a chamber containing oxygenated ACSF (with $2 \mathrm{mM} \mathrm{CaCl}_{2}$ and $2 \mathrm{mM} \mathrm{MgCl}_{2}$, pH 7.2-7.4, 290$310 \mathrm{mOsm})$ and maintained at room temperature $\left(25 \pm 2^{\circ} \mathrm{C}\right)$. After $1 \mathrm{~h}$, slices were placed on the stage of an upright fixed stage Olympus BX51 microscope, submerged in continuously flowing ACSF ( $4 \mathrm{ml} / \mathrm{min}$ ). Whole-cell voltage-clamp recordings were performed with a MultiClamp 700A amplifier in concert with Clampex acquisition software (version 8.1). Data were low-pass filtered at $1 \mathrm{kHz}$ and sampled at $10 \mathrm{kHz}$. The liquid junction potential was $2-3 \mathrm{mV}$ and was not corrected. MSNs were visualized with the aid of infrared video microscopy and were identified by somatic size and basic membrane properties (input resistance, membrane capacitance, and time constant) (Cepeda et al., 1998). Passive membrane properties of MSNs were determined in voltage-clamp mode by applying a depolarizing step voltage command $(10 \mathrm{mV})$ and using the membrane test function integrated in the pClamp8 software. Series re- sistance was $<25 \mathrm{M} \Omega$, compensated $70-80 \%$, and checked periodically. If the series resistance changed $>10 \%$ by the end of the experiment, the cell was discarded. The patch pipette $(4-5 \mathrm{M} \Omega$ ) contained the following solution (in mM): 130 Cs-methanesulfonate, $10 \mathrm{CsCl}, 4 \mathrm{NaCl}, 1 \mathrm{MgCl}_{2}, 5$ MgATP, 5 EGTA, 10 HEPES, 0.5 GTP, 10 phosphocreatine, 0.1 leupeptin, and 4 QX-314 [N-(2,6-dimethylphenylcarbamoylmethyl)triethylammonium bromide], $\mathrm{pH}$ 7.25-7.3 (280-290 mOsm). QX-314 was used to internally block voltage-dependent $\mathrm{Na}^{+}$current. All drugs used for brain slice experiments were purchased from Sigma.

AMPAR-mediated synaptic currents were evoked by electrical stimulation of afferent cortical fibers using a glass pipette filled with ACSF. The monopolar stimulating electrode was placed on the dorsolateral corpus callosum $150-250 \mu \mathrm{m}$ from the recording electrode. Stimuli $(0.1 \mathrm{~ms}$ pulse duration, $0.1-1.0 \mathrm{~mA}$ intensity) were delivered at intervals $>30 \mathrm{~s}$. Evoked AMPAR-mediated EPSCs were recorded at a holding potential of $-70 \mathrm{mV}$ in ACSF containing $10 \mu \mathrm{M}$ bicuculline, a GABA $\mathrm{A}_{\mathrm{A}}$ receptor antagonist. For simplicity, although these responses are mediated by both AMPA and kainate ionotropic glutamate receptors, we will name them AMPAR-mediated responses because it is difficult to separate their individual components. These responses could be almost completely blocked by 6-cyano-7-nitroquinoxaline-2,3-dione (10 $\mu \mathrm{M})$, a non-NMDA receptor antagonist (data not shown).

FM1-43 loading and unloading. Mice were anesthetized with Nembutal before they were killed. Coronal sections (200 $\mu \mathrm{m}$ thick) containing cortex and striatum were cut on a vibratome and allowed to recover for $1 \mathrm{~h}$ in carbogenated $\left(95 \% \mathrm{O}_{2}, 5 \% \mathrm{CO}_{2}\right)$ ACSF solution (in mM): 109 $\mathrm{NaCl}, 5 \mathrm{KCl}, 35 \mathrm{NaHCO}_{3}, 1.25 \mathrm{NaHPO}_{4}, 1.2 \mathrm{MgCl}_{2}, 2 \mathrm{CaCl}_{2}, 20 \mathrm{HEPES}$ acid, and 10 glucose at room temperature. During experiments, slices were maintained in an RC-27L incubation chamber $(56 \mu \mathrm{l} / \mathrm{mm}$; Warner Instruments) perfused at $2 \mathrm{ml} / \mathrm{min}$ with carbogenated ACSF ( $\mathrm{pH} 7.3-$ $7.4,295-305 \mathrm{mOsm})$ at $35^{\circ} \mathrm{C}$.

FM1-43 [N-(3-triethylammoniumpropyl)-4-(4-(dibutylamino)styryl) pyridinium dibromide] ( $8 \mu \mathrm{M}$ in ACSF; Invitrogen) was loaded into presynaptic terminals by a $10 \mathrm{~min}$ train of $200 \mu \mathrm{s}, 400 \mu \mathrm{A}$ pulses at 10 $\mathrm{Hz}$, applied to cortical layers V-VI by bipolar twisted tungsten electrodes, as described previously (Bamford et al., 2004a). Electrical stimulation was provided by a Tektronix R564B wave generator through a stimulation isolator (A.M.P.I.) and monitored by a S88 storage oscilloscope (Grass-Telefactor). To remove adventitious tissue staining after FM1-43 loading, sections were incubated in ADVASEP-7 (1 mm in ACSF; CyDex) (Kay et al., 1999) for 2 min. During unloading at $10 \mathrm{~Hz}, \mathrm{ACSF}$ was supplemented with ADVASEP-7 $(100 \mu \mathrm{M})$ and the AMPAR blocker 2,3-dihydroxy-6-nitro-7-sulfamoylbenzo[f]quinoxaline-2,3-dione (10 $\mu \mathrm{M}$; AG Scientific) to prevent recurrent endocytosis of dye into terminals and feedback synaptic transmission, respectively. To ensure equilibrium, sections were exposed to pharmacological agents for $10 \mathrm{~min}$ before stimulation-mediated unloading. Amphetamine sulfate, $(S)$-sulpiride, quinpirole, and cadmium chloride were obtained from Sigma.

Imaging and data analysis. Corticostriatal terminals labeled with the fluorescent tracer FM1-43 (Betz and Bewick, 1992; Ryan et al., 1993) were visualized in real time using a Zeiss LSM 510 NLO multiphoton laser scanning confocal microscope equipped with a titanium/sapphire laser (excitation at $810 \mathrm{~nm} / \mathrm{emission}$ at $650 \mathrm{~nm}$ ) and a Plan-Neofluar $40 \times / 1.3$ oil objective (Zeiss). Multiphoton microscopy provides excellent three-dimensional spatial resolution in brain slice preparations with minimal photo bleaching and photo damage (Mainen et al., 1999). Images were captured in eight-bit, $123 \times 123 \mu \mathrm{m}$ regions of interest at $512 \times 512$ pixel resolution and acquired at $21.5 \mathrm{~s}$ intervals. The striatal region of interest containing fluorescent puncta was $1.5-2.0 \mathrm{~mm}$ distant from the cortical stimulation electrodes. To stimulate dopamine release, bipolar electrodes were placed in the striatum and visualized on the edge of the region of interest (see Fig. 2A). To compensate for any minor $z$-axis shift, a $z$-series of five images, separated by $1 \mu \mathrm{m}$ in the $z$-plane, was obtained for each period. Images in each $z$-series were aligned and condensed with maximum transparency.

The time projection of images was analyzed for changes in punctum fluorescence using NIH Image J (Wayne Rosband, National Institutes of Health, Rockville, MD) and custom-written software using interactive data language (IDL; Research Systems). The software adopts an object- 
recognition protocol that rapidly processes terminal destaining ( $\mathrm{Za}$ kharenko et al., 2001; Bamford et al., 2004b). The software identifies spherical puncta $0.5-1.5 \mu \mathrm{m}$ in diameter that fluoresce 2 SDs above the background. Each punctum is aligned in the $x, y$, and $z$ plane to prevent spatial drift, and the time-dependent fluorescence intensity of each punctum is displayed graphically. Background fluorescence was subtracted, and the destaining halftime was determined using a graphical software algorithm derived on SigmaPlot software (SPSS). Punctum demonstrating no active destaining were rejected. Nearness of fit to firstorder kinetic release was determined using $A=100 * \exp \left(\ln (0.5){ }^{\star} t / t_{1 / 2}\right)$, an integrated form of the first-order kinetics equation, $-d[A] / d t=k[A]$. The fractional release parameter $f$ was calculated from $\ln \left(F_{1} / F_{2}\right) / \Delta$ STIM (Isaacson and Hille, 1997) in which $\ln$ is the natural logarithm, $F_{1}$ and $F_{2}$ are the fluorescent intensities at $t_{1}$ and $t_{2}$, respectively, and $\Delta$ STIM is the number of stimuli delivered during that period.

Dissociated cell preparation. Acutely dissociated striatal MSNs were obtained using previously described procedures (Bargas et al., 1994; Starling et al., 2005). Briefly, mice were anesthetized with halothane and perfused transcardially with $10 \mathrm{ml}$ of ice-cold, oxygenated sucrose solution containing (in mM) 250 sucrose, 11 glucose, $15 \mathrm{HEPES}, 1 \mathrm{Na}_{2} \mathrm{HPO}_{4}$, $4 \mathrm{MgSO}_{4}$, and $2.5 \mathrm{KCl}, \mathrm{pH} 7.4(300-310 \mathrm{mOsm})$ and were decapitated. Brains were dissected and sliced in oxygenated cold sucrose solution. Coronal $350-\mu$ m-thick slices were incubated in $\mathrm{NaHCO}_{3}$-buffered Earl's balanced salt solution ( $\mathrm{pH} 7.4,300-310 \mathrm{mOsm}$ ) bubbled with $95 \%$ $\mathrm{O}_{2}-5 \% \mathrm{CO}_{2}$ and supplemented with (in $\mathrm{mm}$ ) 1 pyruvic acid, 0.005 glutathione, $0.1 \mathrm{NG}$-nitro-L-arginine, and 1 kynurenic acid until dissociation. After a $1 \mathrm{~h}$ incubation, dorsal striata were dissected, placed in an oxygenated cell-stir chamber (Wheaton), and enzymatically treated for 20 min with papain $(0.5 \mathrm{mg} / \mathrm{ml}$; Calbiochem $)$ at $35^{\circ} \mathrm{C}$ in a HEPESbuffered Hank's balanced salt solution ( $\mathrm{pH} 7.4,300-310$ mOsm). After enzymatic digestion, the tissue was rinsed with a low $\mathrm{Ca}^{2+}$ HEPESbuffered Na-isethionate solution [in mM: $140 \mathrm{Na}^{+}$isethionate, $2 \mathrm{KCl}, 2$ $\mathrm{MgCl}_{2}, 0.1 \mathrm{CaCl}_{2}, 23$ glucose, and 15 HEPES, pH 7.4 (300-310 mOsm)] and mechanically dissociated with a graded series of fire-polished Pasteur pipettes. The cell suspension was plated into a Petri dish containing a HEPES-buffered salt solution consisting of the following (in mM): 140 $\mathrm{NaCl}, 23$ glucose, 15 HEPES, $2 \mathrm{KCl}, 2 \mathrm{MgCl}_{2}$, and $1 \mathrm{CaCl}_{2}$, pH $7.4(300-$ $310 \mathrm{mOsm})$. For whole-cell voltage-clamp recordings, the internal pipette solution contained the following (in $\mathrm{mm}$ ): $175 \mathrm{~N}$-methyl-Dglucamine, $40 \mathrm{HEPES}, 2 \mathrm{MgCl}_{2}, 10$ EGTA, 12 phosphocreatine, 2 $\mathrm{Na}_{2} \mathrm{ATP}, 0.2 \mathrm{Na}_{2} \mathrm{GTP}$, and 0.1 leupeptin, pH 7.2-7.3 (265-270 mOsm) (Sigma). The $\mathrm{Mg}^{2+}$-free external solution consisted of the following (in mM): $135 \mathrm{NaCl}, 20 \mathrm{CsCl}, 3 \mathrm{BaCl}_{2}, 2 \mathrm{CaCl}_{2}, 10$ glucose, 10 HEPES, 0.02 glycine, and 0.0003 tetrodotoxin (TTX), pH 7.4 (300-310 mOsm) (Calbiochem). The presence of $\mathrm{Cs}^{+}$and TTX in the external solution blocked some voltage-gated $\mathrm{K}^{+}$and all $\mathrm{Na}^{+}$currents, respectively. Electrode resistance was typically $5-6 \mathrm{M} \Omega$ in the bath. After seal rupture, the series resistance was compensated (70-90\%) and periodically monitored. Only data from cells for which access resistance values were $<20 \mathrm{M} \Omega$ were included. Signals were detected with an Axoclamp 2B amplifier (Molecular Devices). Membrane capacitances and input resistances were measured by applying a $10 \mathrm{mV}$ depolarizing step voltage command and using the membrane test function integrated in the pClamp software.

Drugs were applied using a pressure-driven perfusion system with an array of capillaries positioned $\sim 500 \mu \mathrm{m}$ from the cell. Solution changes were performed by changing the position of the array with a direct current drive system controlled by an SF-77B perfusion system (Warner Instruments) synchronized by pClamp. Agonists, antagonists, and modulators were applied for $3 \mathrm{~s}$ every $30 \mathrm{~s}$. Responsiveness of cells to AMPA application in the absence or presence of $10 \mu \mathrm{M}$ cyclothiazide (CTZ) was examined at a holding potential of $-70 \mathrm{mV}$.

Statistics. Values in the text and the figures are mean \pm SEM. Analyses were performed with Prism 4 (GraphPad Software), Statistica 6.1, SigmaStat (SPSS), and pClamp 8.2 (Molecular Devices) software suites. Group means for all measures were compared using Student's $t$ tests (for two group comparisons) and appropriately designed ANOVAs followed by Bonferroni's $t$ tests (multiple group comparisons). Comparisons between release halftimes were determined using Mann-Whitney, ANOVA, or Kolmogorov-Smirnov tests. Changes in terminal subpopu- lations were determined graphically using normal probability plots by comparing individual terminal release with normally distributed data. Differences were considered significant if $p<0.05$.

\section{Results \\ Biphasic alterations in evoked corticostriatal synaptic currents}

EPSCs were evoked in MSNs from YAC128 and WT mice at 1 and 7 months to examine alterations in synaptic responses. The mean stimulation threshold required to evoke an EPSC was significantly lower in cells from YAC128 mice than those from WT mice at 1 month $(0.06 \pm 0.01 \mathrm{~mA}$ for YAC128 vs $0.11 \pm 0.02$ for WT; $p<0.05)$ but not at 7 months $(0.14 \pm 0.02 \mathrm{~mA}$ for YAC128 vs $0.16 \pm 0.02 \mathrm{~mA}$ for WT). At 1 month, the mean peak response amplitudes were significantly greater in cells from YAC128 mice compared with those of WTs at stimulation intensities between 0.3 and $1.0 \mathrm{~mA}(p<0.05-0.01)$ (Fig. 1A,B1). At 7 months, however, the mean peak amplitudes in cells from YAC128 mice were smaller than those of WTs, especially at the higher intensities of stimulation $(p<0.05)$ (Fig. $1 A, B 2)$. In cells from WTs, the mean peak current amplitudes increased with age $(p<0.05)$ (Fig. 1C1). In contrast, the mean current amplitudes in YAC128 cells showed a small decrement with age (Fig. 1C2).

Recordings of synaptic responses also were made in slices from WT and YAC128 mice at 12 months of age in which the effects of quinpirole were examined (see below). In this series, we used low stimulation intensities $(0.05-0.3 \mathrm{~mA})$ because we wanted to concentrate on modulation by quinpirole. Peak amplitudes of responses in YAC128 mice at 1 year of age also were significantly smaller than those of WT mice at this age. The peak amplitudes displayed the greatest differences at stimulation intensities $\geq 0.15 \mathrm{~mA}$ ( $p<0.001$, two-way ANOVA). Mean values \pm SE (in picoamperes) at each intensity for cells from WT $(n=9)$ and YAC128 $(n=10)$ mice, respectively, were as follows: $0.05 \mathrm{~mA}, 44.2 \pm 12.6$ versus $21.7 \pm 2.9, p=0.6 ; 0.1 \mathrm{~mA}, 171.0 \pm$ 35.6 versus $106.6 \pm 18.2, p=0.11 ; 0.15 \mathrm{~mA}, 276.6 \pm 42.9$ versus $179.1 \pm 18.2, p=0.02 ; 0.2 \mathrm{~mA}, 294.3 \pm 42.5$ versus $187.2 \pm 18.2$, $p=0.011 ; 0.3 \mathrm{~mA}, 309.4 \pm 42.5$ versus $184.6 \pm 18.1, p=0.004$ (Fisher's post hoc test). These data indicate that the decreases in peak amplitude in YAC128 mice first observed at 7 months remain at 1 year. Thus, cells from YAC128 mice display a biphasic response to synaptic activation of AMPA receptors. Young YAC128 mice displayed increased AMPAR-mediated responses followed by a subsequent reduction in older mice partially attributable to increasing response amplitudes in cells from WTs. There were no significant differences between YAC128 and WT mice in mean rise or decay times or duration at half-amplitude (data not shown). We anticipated that the observed agedependent changes in the corticostriatal synaptic response could be attributable to presynaptic alterations in glutamate release, alterations in postsynaptic AMPARs, or a combination of both effects. Subsequent experiments examined each of these possibilities.

\section{Biphasic alteration in evoked corticostriatal release}

To examine presynaptic function, we assessed FM1-43 release from cortical terminals within the dorsal striatum (Fig. 2A). Stimulation of axons or cell bodies of projection neurons in layers $\mathrm{V}-\mathrm{VI}$ of the cortex overlying the motor striatum resulted in endocytosis of FM1-43 dye by recycling synaptic vesicles, revealing linear en passant arrays of fluorescent puncta, characteristic of corticostriatal afferents (Fig. 2 B) (Bamford et al., 2004a,b, 2008). After dye loading, cortical restimulation resulted in exocytosis of 
A

Stimulation

Intensity (mA) $0.4 \mathrm{~mA}$

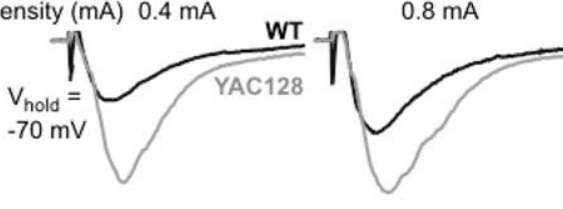

1 Month

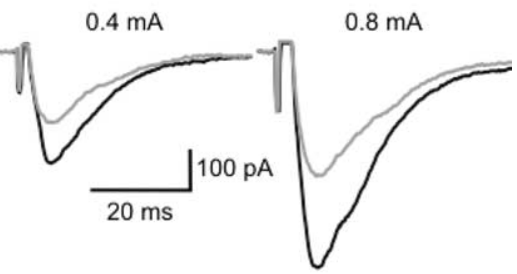

B1

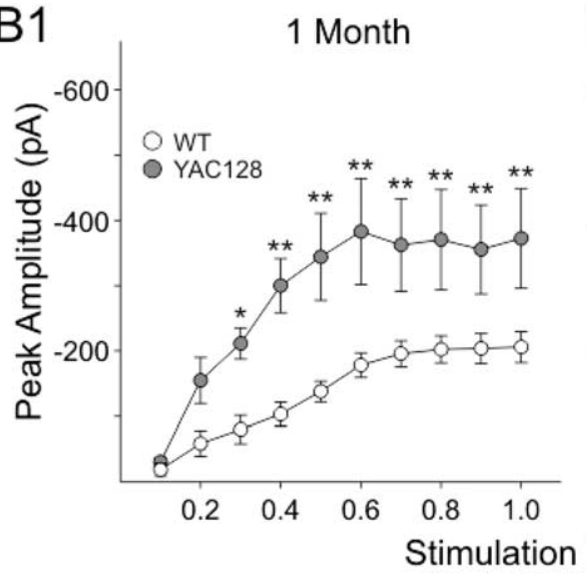

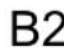

$\mathrm{B} 2$
-600

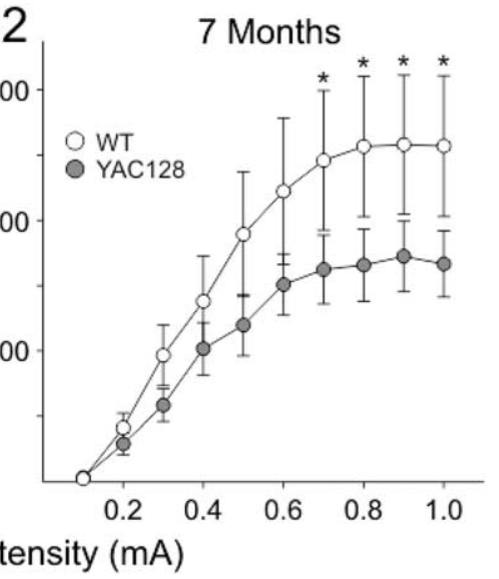

C1

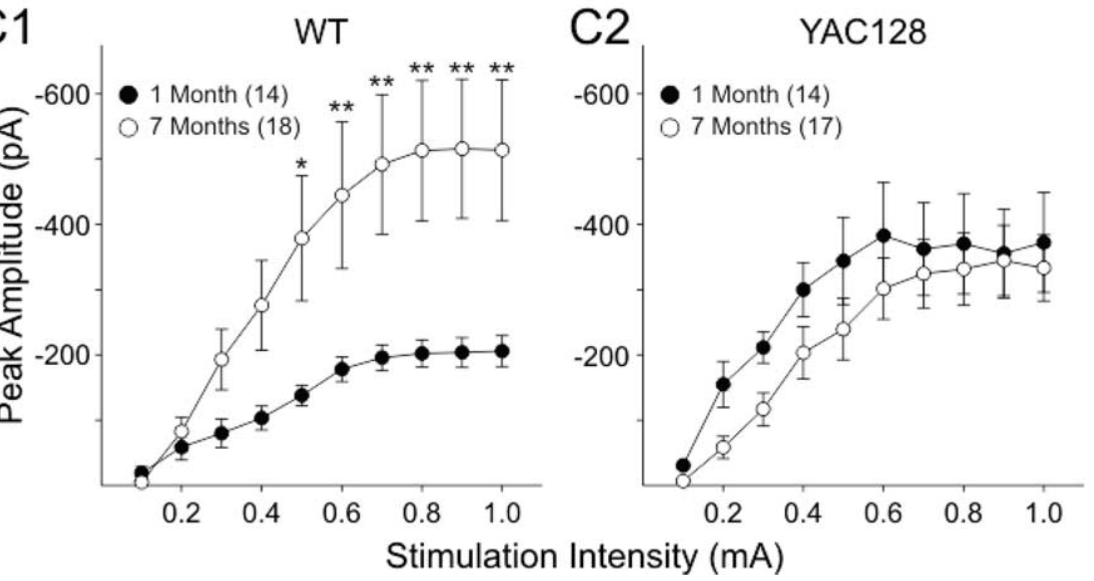

Figure 1. AMPA receptor-mediated synaptic responses in YAC128 mice. $A$, Representative traces showing inward currents evoked by the same two intensities of stimulation in cells from YAC128 and WT mice at each age. $B$, Graphs showing mean \pm SE peak current evoked by the series of increasing intensities of stimulation at 1 month (B1) and 7 months (B2). C, Graphs showing comparisons of mean \pm SE peak current responses for cells from WT (C1) and YAC128(C2) mice at each age. Numbers of cells for each age group for all graphs are shown in $\mathbf{C}$ and $\mathbf{C}$.

FM1-43 dye from the terminals, which decreased in a manner approximated by a single exponent, characteristic of synaptic vesicle fusion (Fig. 2C,D) (Stevens and Tsujimoto, 1995; Wölfel and Schneggenburger, 2003). FM1-43 destaining was calcium dependent because cadmium prevented stimulated release of the dye from presynaptic terminals (Fig. 2E). Because FM1-43 destaining generally followed first-order kinetics, corticostriatal release was characterized by the halftime $\left(t_{1 / 2}\right)$ of release, defined as the time required for terminal fluorescence to decay to half its initial value.

The effects of mutant huntingtin on corticostriatal release were examined in slices from YAC128 mice at 1, 7, and 12 months. We observed the effect of frequency dependence by unloading corticostriatal terminals at 1,10 , and $20 \mathrm{~Hz}$. In slices from 1-month-old WT mice, destaining was dependent on the frequency of applied stimulation and exhibited the greatest slope at
$10 \mathrm{~Hz}$ (Fig. 3A), suggesting that this frequency would be sensitive for detecting responses to genotype and pharmacological manipulations (Stern et al., 1997; Bamford et al., 2004b). At this stimulation frequency, the mean halftime of release from corticostriatal terminals in slices from YAC128 mice was $17 \%$ lower at 1 month of age compared with WT $\left(t_{1 / 2}=180 \mathrm{~s}\right.$ for YAC128 vs $t_{1 / 2}=211 \mathrm{~s}$ for WT; $\left.p<0.001\right)$ (Fig. $3 A, B, H$ ), indicated by a faster release of FM1-43. At 7 months, however, there was a $6 \%$ increase in average release halftimes from YAC128 mice compared with WTs $\left(t_{1 / 2}=243 \mathrm{~s}\right.$ for YAC128 vs $t_{1 / 2}=$ $230 \mathrm{~s}$ for WT; $p=0.24$ ) (Fig. 3C,H). By 12 months, corticostriatal halftimes of release in slices from YAC128 mice significantly increased by $28 \%\left(t_{1 / 2}=300 \mathrm{~s}\right.$ for YAC128 vs $t_{1 / 2}=234 \mathrm{~s}$ for WT; $p<0.001$ ) (Fig. $3 D, H)$. Thus, compared with WTs, corticostriatal release was enhanced in young YAC128 mice but subsequently declined with age.

An advantage of this optical technique is that we are able to examine and compare corticostriatal vesicular release kinetics from individual terminals. When the halftimes of individual terminals are presented relative to their $\mathrm{SD}$ from the mean value, a straight line indicates a normally distributed (or single) population (Bamford et al., 2004b). At 1 month, mutant huntingtin increased vesicular release from all terminals (Fig. 3E). At 7 months in slices from the YAC128 mice, exocytosis from fast-releasing terminals remained potentiated, but terminals with halftimes lower than $1 \mathrm{SD}$ below the mean became inhibited (Fig. 3F). Although the mean value of release was similar between WT and YAC128 at 7 months, there was a significant change in the distribution of terminals $(p<0.001$, Kolmogorov-Smirnov test). In 12-month-old YAC128 slices, all terminals became slower so that the fasterreleasing subpopulation became similar to WTs, whereas the slower population of terminals was further inhibited (Fig. $3 G$ ).

In WTs, corticostriatal release decreased progressively with age. The halftime of release increased from $t_{1 / 2}=211 \mathrm{~s}$ at 1 month, to $t_{1 / 2}=230 \mathrm{~s}$ at 7 months, and to $t_{1 / 2}=234 \mathrm{~s}$ at 12 months $\left(F_{(2,814)}=46 ; p=0.01\right.$, ANOVA) (Fig. $\left.3 H, I\right)$. In YAC128 mice, terminal release kinetics also declined with age but did so to a greater extent than in WTs, decreasing from $t_{1 / 2}=$ $180 \mathrm{~s}$ at 1 month, to $t_{1 / 2}=243 \mathrm{~s}$ at 7 months, and to $t_{1 / 2}=300 \mathrm{~s}$ at 12 months $\left(F_{(2,685)}=59 ; p<0.001\right.$, ANOVA) (Fig. $\left.3 H, J\right)$. Thus, although corticostriatal release in WT mice decreased by $11 \%$ between 1 and 12 months, YAC128 mice demonstrated a 67\% decrease over the same period.

Although terminal release halftimes in WTs decreased with age, the population of terminals remained mostly normal (Fig. $3 I$ ). Examination of individual terminals in slices from YAC128 
mice at 7 months also demonstrated linearity, consistent with normally distributed release kinetics (Fig. $3 J$ ). At 1 month, however, there was preferential excitation in those terminals with halftimes of release greater than $1 \mathrm{SD}$ below the mean. At 12 months, those terminals appeared preferentially inhibited (Fig. 3J). Thus, compared with WTs, cortical input to the YAC128 striatum was enhanced in young mice but showed a progressive decline with age, with time-dependent alterations in specific subpopulations of corticostriatal terminals at each age.

\section{Functional activity of corticostriatal afferents}

We determined whether these age-related changes in corticostriatal activity might be produced through alterations in endocytosis, a reduction in active terminals, or by modifications in the fractional release of FM1-43. Changes in release of FM1-43 in slices from 1-month-old mice were not attributable to inadequate FM1-43 loading of the recycling synaptic vesicle pool because loading stimulation frequencies of 1 , 10 , or $20 \mathrm{~Hz}$ (for $10 \mathrm{~min}$ ) did not significantly affect unloading at $10 \mathrm{~Hz}$ in either $\mathrm{WT}\left(t_{1 / 2}=210 \mathrm{~s}\right.$ at $1 \mathrm{~Hz}, 211 \mathrm{~s}$ at $10 \mathrm{~Hz}$, and $205 \mathrm{~s}$ at $20 \mathrm{~Hz} ; n=32-425$ puncta; $p>0.5$, Mann-Whitney test) or in YAC128 $\left(t_{1 / 2}=177 \mathrm{~s}\right.$ at $1 \mathrm{~Hz}, 179 \mathrm{~s}$ at 10 $\mathrm{Hz}$, and $177 \mathrm{~s}$ at $20 \mathrm{~Hz} ; n=39-353$ puncta; $p>0.1$, Mann-Whitney test) mice. Likewise, synaptic vesicle fusion was conserved in all age groups, because corticostriatal release in slices from both WT and YAC128 mice approximated first-order release kinetics $\left(r^{2}>0.99\right)$ (Fig. $\left.3 B-D\right)$ and remained dependent on calcium (Fig. $2 E$ ). However, although the number of active terminals in each slice was similar in WT and YAC128 mice at 1 month $32.4 \pm$ 4 vs $33.3 \pm 2$ puncta for WT and YAC128 mice, respectively; $n=34-35$ slices; $p=$ 0.4, ANOVA) and at 7 months $(36.9 \pm 3$ vs $38.1 \pm 5$ puncta for WT and YAC128 mice, respectively; $n=16-34$ slices; $p=0.4$, ANOVA), it was significantly reduced in YAC128 mice at 12 months $(33.8 \pm 4$ puncta for WTs vs $21.9 \pm 3$ puncta for YAC128 mice; $n=19-21$ slices; $p=0.02$, ANOVA), suggesting a reduction in functional corticostriatal afferents in older YAC128 mice.

In WTs, the mean fractional destaining of FM1-43 per stimulus $(f)$ at 1 month was $0.033 \pm 0.002 \%$ (Fig. $3 K$ ), similar to previous reports (Bamford et al., 2004b, 2008). There was a decline in the fractional release with age to $f=0.032 \pm 0.002 \%$ at 7 months and to $f=0.025 \pm 0.002 \%$ at 12 months $\left(F_{(2,90)}=3 ; p<\right.$ 0.05, ANOVA). Fractional destaining decreased more rapidly in slices from YAC128 mice, declining from $f=0.038 \pm 0.003 \%$ at 1 month, to $f=0.027 \pm 0.003 \%$ at 7 months, and to $f=0.021 \pm$ $0.001 \%$ at 12 months $\left(F_{(2,90)}=11 ; p<0.001\right.$, ANOVA), with the greatest depression seen at 1 year $(p<0.05$, ANOVA). The re-
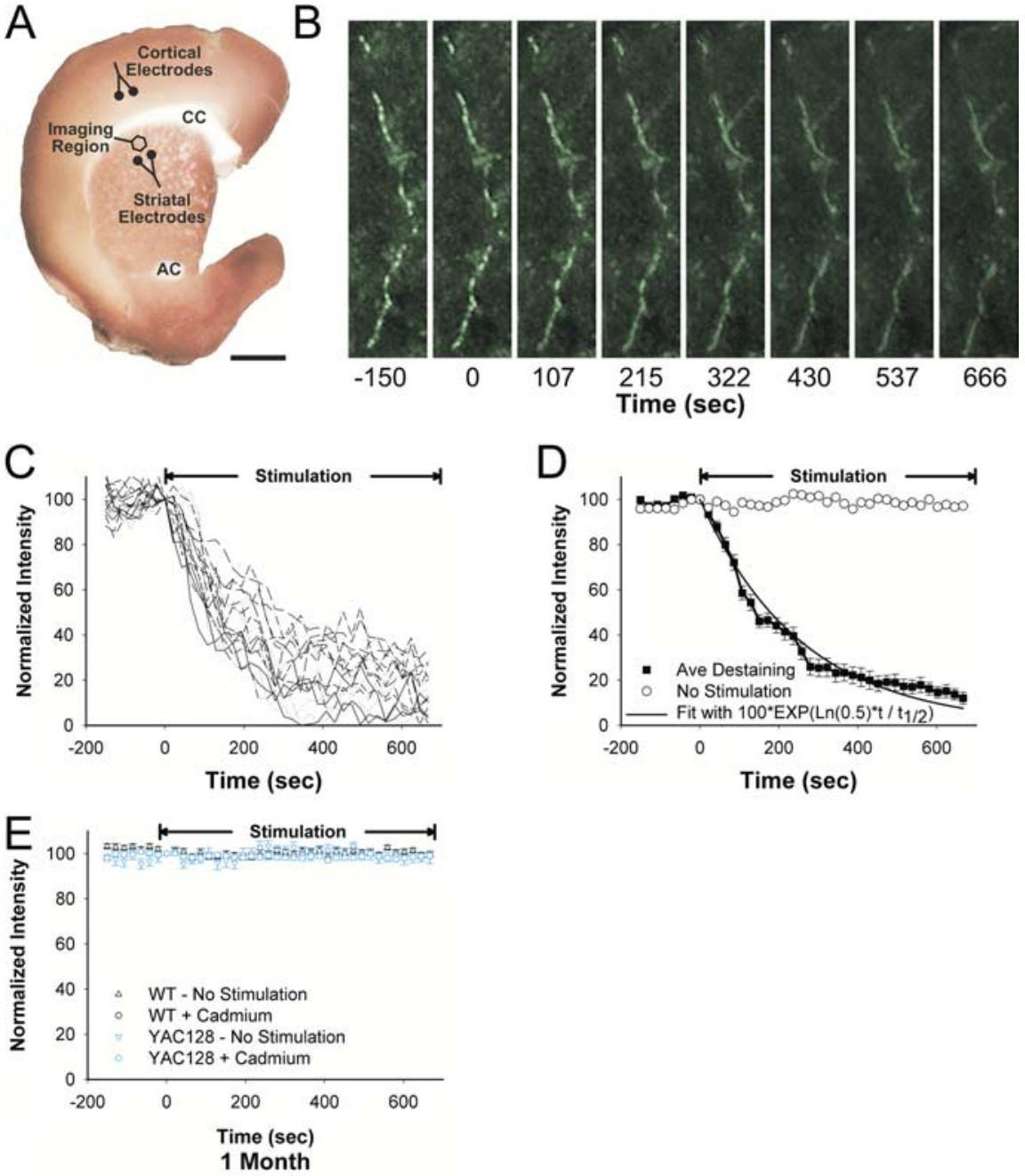

Figure 2. Loading and unloading of corticostriatal terminals with FM1-43. A, A corticostriatal slice stained with 3,3'diaminobenzidine shows the areas of stimulation and recording. Corticostriatal terminals were loaded with FM1-43 by stimulamouse. Images captured every $21.5 \mathrm{~s}$ reveal en passant arrays of corticostriatal terminals. Restimulation at $t=0$ with $10 \mathrm{~Hz}$ pulses ows activity-dependent destaining of fluorescent puncta. Scale bar, $2 \mu \mathrm{m}$. C, Time-intensity analysis of FM1-43 release from

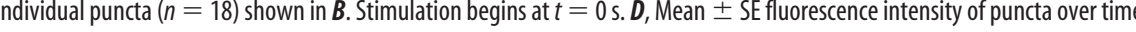
shown in $\boldsymbol{B}$ is compared with a single exponent curve. The plateau line represents fluorescence measurements from nondestaining puncta. $\boldsymbol{E}$, No destaining was observed in WT or YAC128 slices receiving either no stimulation $(n=24-29)$ or at $10 \mathrm{~Hz}$ stimulation after superfusion in cadmium ( $n=44-23)$.

duced fractional release of label during exocytosis in slices from YAC128 mice could be attributable to a reduced probability of recycling synaptic vesicles that undergo exocytic fusion per stimulus, a reduced amount of FM1-43 released per exocytic event, or a combination of these mechanisms (Bamford et al., 2008).

\section{Dopamine filters corticostriatal release}

Previous experiments using untreated adult mice demonstrated that dopamine filters cortical information to the striatum by inhibiting exocytosis from less active corticostriatal terminals via activation of $\mathrm{D}_{2}$ receptors (Bamford et al., 2004a,b, 2008). In slices from WTs at 1 month, amphetamine [which induces continuous dopamine efflux via reverse transport (Schmitz et al., 2001)] decreased corticostriatal release by $35 \%$ at $10 \mathrm{~Hz}$ cortical stimulation $\left(t_{1 / 2}=284 \mathrm{~s}\right.$ vs $211 \mathrm{~s}$ for untreated WTs; $\left.p<0.001\right)$ 


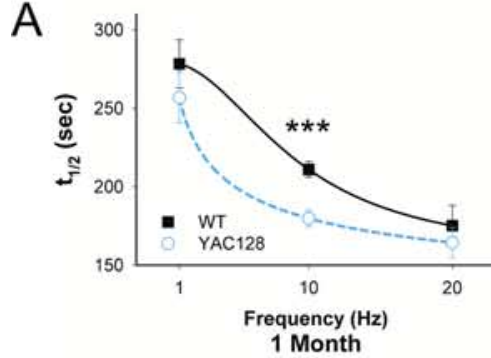

C

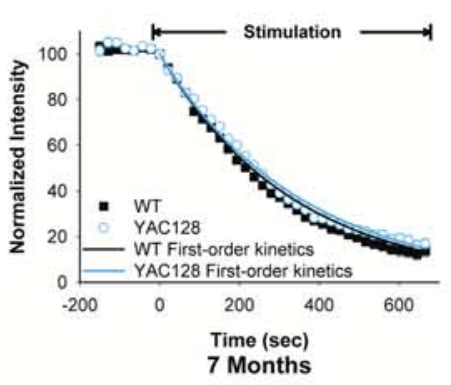

E

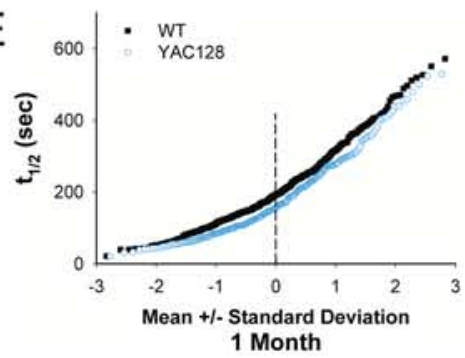

G
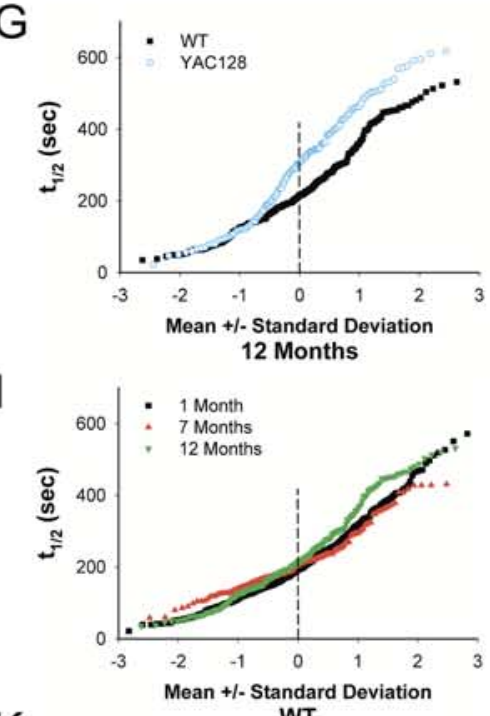

K

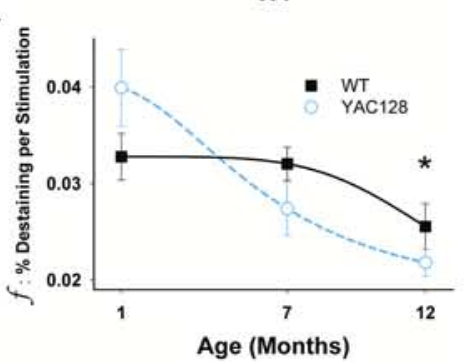

B

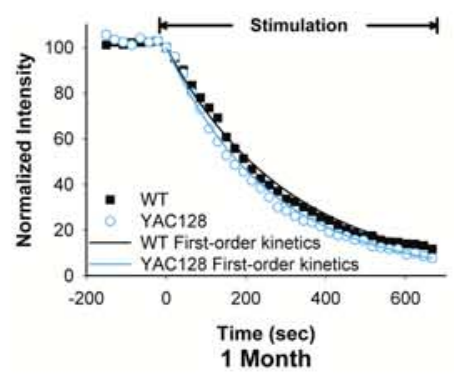

D

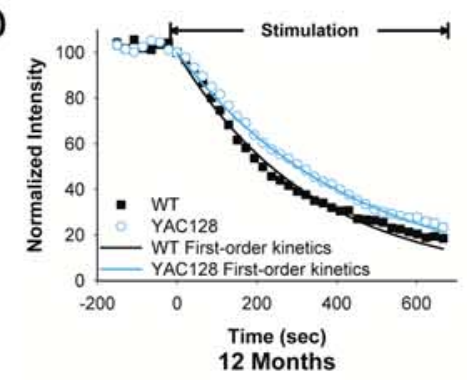

$\mathrm{F}$

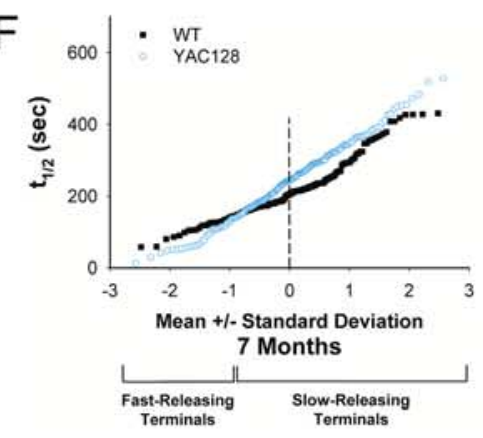

$\mathrm{H}$

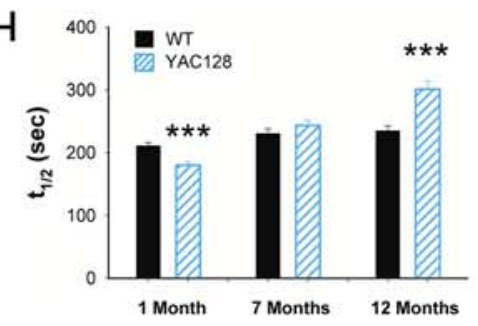

$\mathrm{J}$

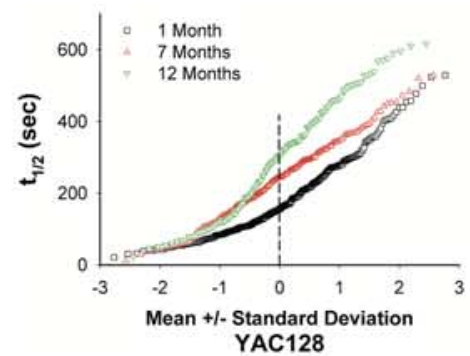

(Fig. 4A-D). Similar to amphetamine, the $\mathrm{D}_{2}$ receptor agonist quinpirole $(0.5 \mu \mathrm{M})$ also depressed corticostriatal exocytosis $\left(t_{1 / 2}=258 ; p<0.001\right.$ ) (Fig. $\left.4 B-D\right)$. As expected, the $D_{2}$ receptor antagonist sulpiride $(10 \mu \mathrm{M})$ completely blocked inhibition by amphetamine $\left(t_{1 / 2}=205 \mathrm{~s}\right.$ for amphetamine and sulpiride; $p>0.5$ compared with untreated slices) (Fig. $4 B-D$ ). Both amphetamine and quinpirole created two reversible populations of terminals that diverged at $1 \mathrm{SD}$ below the mean (Fig. $4 D$ ), preferentially inhibiting slowreleasing terminals $(\sim 80 \%)$.

In slices from 1-month-old YAC128 mice, amphetamine also inhibited FM1-43 destaining with the greatest effect seen at $10 \mathrm{~Hz}$ cortical stimulation $\left(t_{1 / 2}=250 \mathrm{vs}\right.$ $180 \mathrm{~s}$ for untreated slices from YAC128 mice; $p<0.001$ ) (Fig. $4 E-H$ ). Quinpirole also inhibited release $\left(t_{1 / 2}=257 ; p<\right.$ 0.001 ) (Fig. $4 F-H$ ), and the inhibitory effect of amphetamine was blocked by sulpiride $\left(t_{1 / 2}=179 \mathrm{~s}\right.$ for amphetamine and sulpiride; $p>0.5$ compared with untreated slices from YAC128 mice) (Fig. $4 F-H)$. Thus, in both WT and YAC128 slices, amphetamine or quinpirole produced a $D_{2}$ receptor-dependent filter with filtering applied preferentially to terminals with the lowest probability of release (Bamford et al., 2004b; Dani and Zhou, 2004).

$\mathrm{D}_{2}$ receptor-dependent corticostriatal

\section{$\leftarrow$}

Figure 3. Age-dependent changes in corticostriatal release. $\boldsymbol{A}, \mathrm{FM1}-43$ destaining is dependent on the frequency of cortical stimulation. $n=89-425$ puncta for each condition; ${ }^{* * *} p<0.001$, Mann-Whitney test. $\boldsymbol{B}$, Time-intensity analysis of FM1-43 destaining in slices from YAC128 mice at 1 month demonstrates an increase in release compared with same-aged WTs. Release from both WT and YAC128 mice approximate first-order kinetics. C, Time-intensity analysis of FM1-43 release in slices from YAC128 mice at 7 months demonstrates a similar rate of destaining compared with WTs. Release from both WT and YAC128 mice approximated firstorder kinetics. $\boldsymbol{D}$, At 12 months, FM1-43 release in slices from YAC128 mice showed a slower rate of destaining compared with WTs, with release approximating single-exponent kinetics. $E$, Normal probability plot of individual terminal halftimes of release from averaged puncta shown in $\boldsymbol{B}$. $\boldsymbol{F}$, Individual terminal halftimes of release from averaged puncta shown in C. $G$, Individual terminal halftimes of release from averaged puncta shown in $\boldsymbol{D}$. $\boldsymbol{H}$, Distribution of mean $t_{1 / 2}$ of release for destaining curves shown in $\boldsymbol{B}-\boldsymbol{D}$. For WTs, $n=425,160$, and 258 puncta at 1,7 ,and 12 months, respectively. For YAC128 mice, $n=353,196$, and 139 puncta at 1,7 , and 12 months, respectively. ${ }^{* * *} p<0.001$ compared with WT littermates, Mann-Whitney test. $I$, Individual terminal halftimes of release in WTs at 1,7 , and 12 months. J, Individual terminal halftimes of release in YAC128 mice at 1,7 , and 12 months. $\boldsymbol{K}$, The fractional release of FM1-43 declined with age. $n=31$ for each condition, ${ }^{*} p<0.05$, ANOVA. Curves for $\boldsymbol{A}$ and $\boldsymbol{K}$ were fit with a Hill equation. 
filtering was also seen at 7 months in slices from both WT and YAC128 mice. In WTs, quinpirole depressed release $\left(t_{1 / 2}=277 \mathrm{vs}\right.$ $230 \mathrm{~s}$ for untreated slices; $p<0.001$ ) (Fig. $5 A-C)$ as did amphetamine $\left(t_{1 / 2}=289 \mathrm{~s}\right.$; $p<0.001)$. Sulpiride blocked the inhibitory effect of amphetamine $\left(t_{1 / 2}=221 \mathrm{~s}\right.$ for amphetamine and sulpiride; $p=0.5$ compared with untreated slices) (Fig. 5AC). Similar to 1-month-old WT mice, both quinpirole and amphetamine filtered corticostriatal release by selective inhibition of the slowest releasing terminals (Fig. $5 C)$. In YAC128 slices, quinpirole $\left(t_{1 / 2}=\right.$ 311 vs $243 \mathrm{~s}$ for untreated slices from YAC128 mice; $p<0.001$ ) (Fig. $5 D-F$ ) or amphetamine $\left(t_{1 / 2}=308 \mathrm{~s} ; p<0.001\right) \mathrm{re}$ duced release and did so through highpass corticostriatal filtering (Fig. $5 F$ ). Sulpiride alone did not alter release $\left(t_{1 / 2}=\right.$ $246 ; n=287$ puncta; $p=0.8$, MannWhitney test) and blocked the inhibitory effect of amphetamine $\left(t_{1 / 2}=235 \mathrm{~s}\right.$ for amphetamine and sulpiride; $p=0.7$ compared with untreated slices from YAC128 mice) (Fig. 5D-F).

\section{Dopamine filtering is less effective in older YAC128 mice}

In 12-month-old WTs, both quinpirole $\left(t_{1 / 2}=288\right.$ vs $234 \mathrm{~s}$ for untreated slices; $p<$ $0.001)$ (Fig. $6 A-C)$ and amphetamine $\left(t_{1 / 2}\right.$ $=276 \mathrm{~s} ; p<0.001)$ inhibited corticostriatal release but did so through nonselective inhibition of all terminals (Fig. 6C). Sulpiride alone had no effect on release $\left(t_{1 / 2}=226 \mathrm{~s} ; n=198\right.$ puncta; $p=0.4$, Mann-Whitney test) and blocked amphetamine-induced inhibition $\left(t_{1 / 2}=\right.$ $240 \mathrm{~s}$ for amphetamine and sulpiride; $p=$ 0.5 compared with untreated slices) (Fig. $6 A-C)$.

Compared with WTs, exocytosis was reduced in slices from 12-month-old YAC128 animals $\left(t_{1 / 2}=300\right.$ vs $234 \mathrm{~s}$ for same-aged WTs; $p<0.001$, Mann-Whitney test) (Fig. $3 G$ ), but both quinpirole $\left(t_{1 / 2}=336 \mathrm{~s} ; p<0.05\right.$ ) (Fig. $\left.6 D-F\right)$ and amphetamine $\left(t_{1 / 2}=340 \mathrm{~s} ; p<0.01\right)$ remained inhibitory. Sulpiride alone did not change release $\left(t_{1 / 2}=299 \mathrm{~s} ; n=96\right.$ puncta; $p=0.8$, Mann-Whitney test) and prevented amphetamine-induced inhibition $\left(t_{1 / 2}=307 \mathrm{~s}\right.$ for amphetamine combined with sulpiride; $p=0.7$ compared with untreated YAC128 slices) (Fig. 6D-F). Thus, in slices from older WT and YAC128 animals, dopamine-dependent high-pass filtering found in slices from younger mice was absent because activation of $\mathrm{D}_{2}$ receptors more broadly inhibited cortical input.

To parallel the release experiments, modulation of synaptic responses by quinpirole were also tested at 1 year. $D_{2}$ receptor
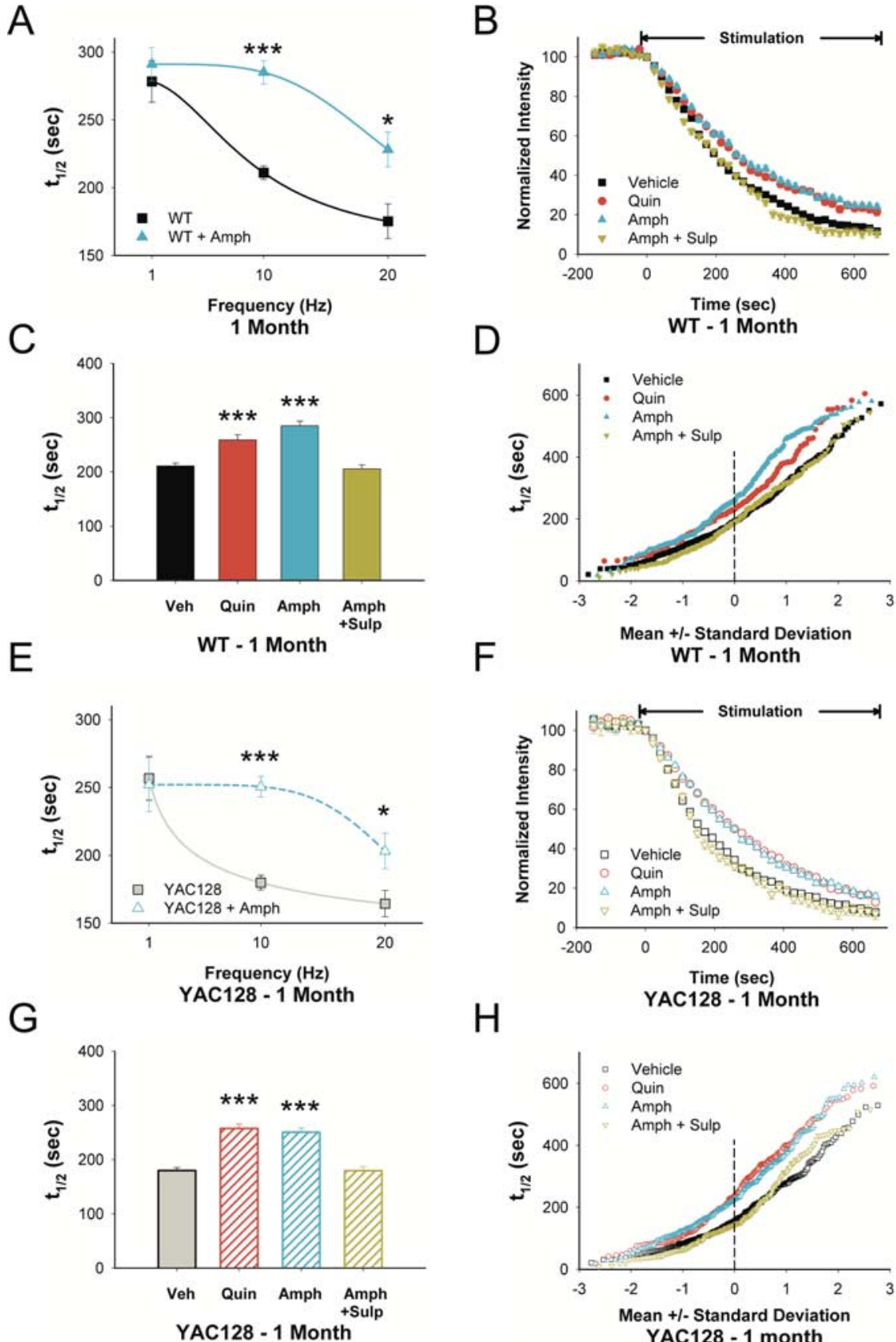

Figure 4. $\quad D_{2}$ receptors modulate corticostriatal release in 1-month-old YAC128 mice. $A$, Release halftimes for 1-month-old WT slices after cortical stimulation at 1,10 , and $20 \mathrm{~Hz}$ in the presence and absence of amphetamine in vitro $(n=89-425$ puncta for each condition; ${ }^{*} p<0.05,{ }^{* * *} p<0.001$, Mann-Whitney test). $\boldsymbol{B}$, Compared with untreated slices (Veh), both the $\mathrm{D}_{2}$ receptor agonist quinpirole (Quin) and amphetamine (Amph) decreased FM1-43 destaining in slices from 1-month-old WT mice. The inhibitory effect of Amph was reversed by the $D_{2}$ receptor antagonist sulpiride (Amph + Sulp). C, Distribution of mean $t_{1 / 2}$ of release for destaining curves shown in B. $n=346,194,246$, and 224 puncta for Veh, Quin, Amph, and Amph + Sulp, respectively. ${ }^{* * *} p<0.001$ compared with Veh, Mann-Whitney test. $\boldsymbol{D}$, Individual terminal halftimes of release from averaged puncta shown in $\boldsymbol{B}$. $\boldsymbol{E}$, Release halftimes for 1-month-old YAC128 slices after cortical stimulation at 1, 10, and $20 \mathrm{~Hz}$ in the presence and absence of amphetamine in vitro ( $n=62-353$ puncta for each condition; ${ }^{*} p<0.05$, ${ }^{* * *} p<0.001$, Mann-Whitney test). Curves for $A$ and $\boldsymbol{E}$ were fit with a Hill equation. $\boldsymbol{F}$, Compared with untreated slices (Veh), both the $D_{2}$ receptor agonist Quin and Amph decreased FM1-43 destaining in slices from 1-month-old YAC128 mice. The inhibitory effect of Amph was reversed by addition of the $\mathrm{D}_{2}$ receptor antagonist Sulp (Amph + Sulp). G, Distribution of mean $t_{1 / 2}$ of release for destaining curves shown in $\boldsymbol{F} . n=284$, 271, 285, and 277 puncta for Veh, Quin, Amph, and Amph + Sulp, respectively. ${ }^{* *} p<0.001$ compared with Veh, MannWhitney test. $\boldsymbol{H}$, Individual terminal halftimes from averaged puncta shown in $\boldsymbol{F}$. activation produced a reduced effect in cells from YAC128 mice compared with those from WTs at 1 year of age. Mean percentage change was averaged for each cell across stimulation intensities. Quinpirole reduced WT peak amplitudes by $-18.7 \pm 5.8$ and 
A

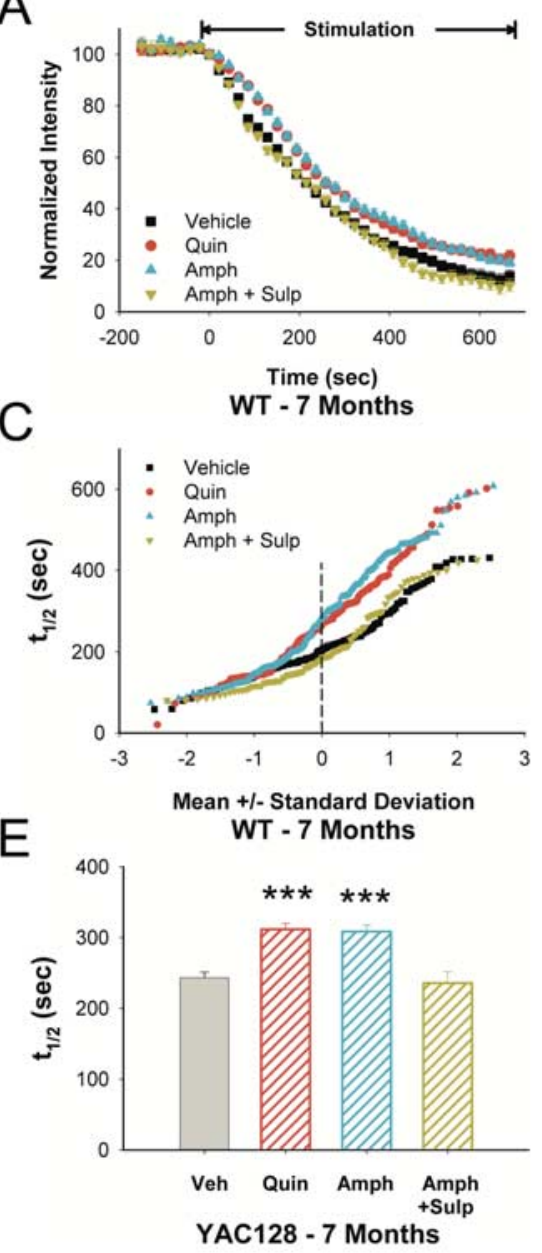

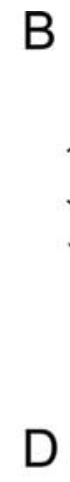
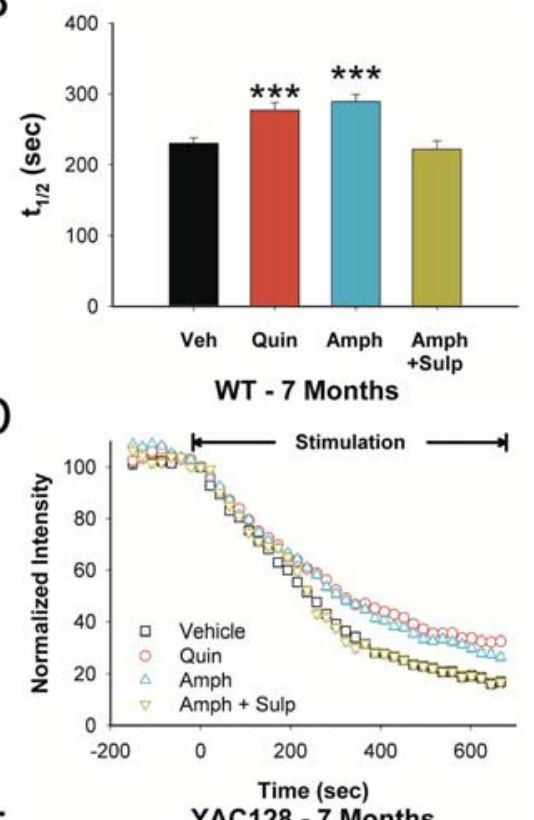

$\mathrm{F}$

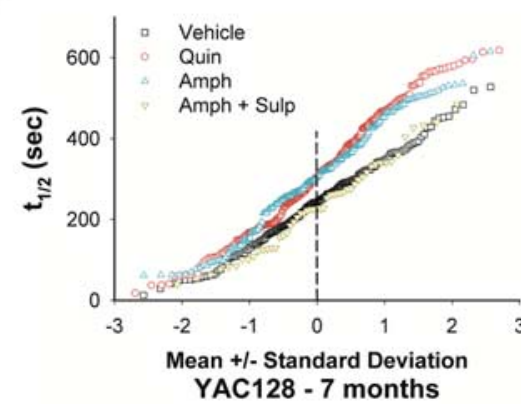

Figure 5. $D_{2}$ receptor responses in 7-month-old YAC128 mice. $\boldsymbol{A}$, In 7-month-old WTs, both quinpirole (Quin) and amphetamine (Amph) decreased FM1-43 destaining. The inhibitory effect of Amph was reversed by sulpiride (Sulp). $\boldsymbol{B}$, Distribution of mean $t_{1 / 2}$ of release for destaining curves shown in $A . n=160,135,178$, and 118 puncta for vehicle (Veh), Quin, Amph, and Amph + Sulp, respectively. ${ }^{* *} p<0.001$ compared with Veh, Mann-Whitney test. $\boldsymbol{C}$, Individual terminal halftimes of release from averaged puncta shown in $\boldsymbol{A}$. $\boldsymbol{D}$, In 7-month-old YAC128 mice, both Quin and Amph decreased FM1-43 destaining. The inhibitory effect of Amph was reversed by Sulp. $\boldsymbol{E}$, Distribution of mean $t_{1 / 2}$ of release for destaining curves shown in $\boldsymbol{D}$. $n=196$, 282, 193, and 52 puncta for Veh, Quin, Amph, and Amph + Sulp, respectively. ${ }^{* * *} p<0.001$ compared with Veh, Mann-Whitney test. $\boldsymbol{F}$, Individual terminal halftimes of release from averaged puncta shown in $\boldsymbol{D}$.

$-29.1 \pm 5.5 \%$ from baseline at 1 and $10 \mu \mathrm{M}$ concentrations, respectively. In contrast, peak amplitudes of cells from YAC128 mice increased by $15.8 \pm 6.7 \%(p=0.0012$ compared with values from WTs $)$ and $6.5 \pm 11.6 \%(p=0.016$ compared with values from WTs) at quinpirole concentrations of 1 and $10 \mu \mathrm{M}$, respectively.

Although both amphetamine and quinpirole continued to inhibit release in older WT and YAC128 mice, corticostriatal filtering became impaired, and the average response to $\mathrm{D}_{2}$ receptor manipulation declined with age. At 1 month, amphetamine decreased exocytosis (increased average terminal halftimes) by $35 \pm$ $8 \%$ in slices from WT mice and by $35 \pm 5 \%$ from YAC128 mice (Fig. 6G). At 7 months, the response to amphetamine declined to $28 \pm 2 \%$ in WTs and to $22 \pm 6 \%$ in YAC128 mice. At 12 months, amphetamine decreased exocytosis by $20 \pm 1 \%$ in WTs but by only $10 \pm 3 \%$ in YAC128 mice. Although the inhibition by dopamine of corticostriatal release decreased in both WT and YAC128 slices, there was a greater reduction in YAC128 mice by 12 months $(p<0.05)$ (Fig. 6G). Therefore, the expected decline in the ability of amphetamine to release synaptic dopamine in senescence (Gerhardt and Maloney, 1999) was greater in YAC128 slices. Interestingly, in WT slices, quinpirole reduced release by $18-21 \%$, with little variability over the age of the mouse (Fig. $6 \mathrm{H}$ ), suggesting that $\mathrm{D}_{2}$ receptor sensitivity does not change because decreases in dopamine reuptake may compensate for the age-dependent decline in dopamine availability (Gerhardt and Maloney, 1999; Hebert and Gerhardt, 1999). However, in slices from YAC128 mice, quinpirole decreased exocytosis by $35 \pm 5 \%$ at 1 month, but by $26 \pm 4 \%$ at 7 months, and by only $9 \pm 2 \%$ at 12 months $(p<0.001$, ANOVA) (Fig. 6H). Therefore, although the response to direct $\mathrm{D}_{2}$ receptor stimulation in WTs remained constant, the effect of quinpirole in YAC128 mice was amplified at 1 month but became diminished at 12 months $(p<0.05$ interaction between YAC128 mutation and age, two-way ANOVA).

To confirm that slices from older YAC128 mice did not respond to $\mathrm{D}_{2}$ receptor stimulation to the same degree as their WT littermates, we released striatal dopamine in a different manner using local bipolar stimulation (Fig. 2A). Rodents exposed to behaviorally salient stimuli display a rapid pulsatile elevation of striatal dopamine that reaches 200-500 nM and declines to background levels in $<1 \mathrm{~s}$ (Robinson et al., 2001). In the slice preparation, striatal stimulation at $0.1 \mathrm{~Hz}$ evokes local dopamine release in a manner similar to behavioral stimuli associated with activation of reward pathways, reaching a peak level of $\sim 1-2 \mu \mathrm{M}$ for the first stimulus and eventually decreasing to a plateau of $\sim 30 \%$ of initial concentration (Bamford et al., 2004b). At this frequency, electrically evoked synaptic dopamine inhibits glutamate release in normal mice to the same extent as amphetamine, and striatal stimulation alone has no measurable effect on punctum fluorescence, suggesting negligible direct interactions with glutamatergic afferents (Bamford et al., 2004b). In slices from 7-month-old YAC128 mice, striatal stimulation reduced exocytosis by $22 \%$ $\left(t_{1 / 2}=297\right.$ vs $243 \mathrm{~s}$ for unstimulated sections; $n=110$ puncta; $p<0.001$, Mann-Whitney test), a halftime of release similar to that observed in YAC128 slices with quinpirole $\left(t_{1 / 2}=311 \mathrm{~s} ; p=\right.$ 0.4 , Mann-Whitney test $)$ or amphetamine $\left(t_{1 / 2}=308 \mathrm{~s} ; p=0.7\right.$, Mann-Whitney test). In 12-month-old YAC128 mice, striatal stimulation reduced corticostriatal release by $14 \%\left(t_{1 / 2}=343 \mathrm{vs}\right.$ 300 s for unstimulated sections; $n=110$ puncta; $p=0.02$, MannWhitney test $)$, similar to that achieved by quinpirole $\left(t_{1 / 2}=336 \mathrm{~s}\right.$; $p=0.1$, Mann-Whitney test $)$ or amphetamine $\left(t_{1 / 2}=340 \mathrm{~s} ; p=\right.$ 0.5 , Mann-Whitney test). As expected, sulpiride blocked the effect of striatal stimulation $\left(t_{1 / 2}=296 \mathrm{~s} ; n=110\right.$ puncta; $p=0.2$ compared with unstimulated sections, Mann-Whitney test). Thus, $\mathrm{D}_{2}$ receptor stimulation with quinpirole, dopamine released via amphetamine, or dopamine released by direct striatal stimulation were all less effective in modulating corticostriatal vesicular release in 12-month-old YAC128 mice. 
Biphasic alterations in biophysical membrane properties and postsynaptic AMPAR-mediated currents

To more specifically examine postsynaptic changes in AMPAR function, we assessed changes in evoked currents in acutely dissociated MSNs at 1 and 7 months. Based on electrophysiological measurements and cell appearance, all electrophysiological recordings were from MSNs (Fig. $7 A, B)$. The mean cell capacitance, input resistance, and membrane time constants were similar in YAC128 and WT mice at 1 month (Fig. $7 B$ ). However, a decrease in mean membrane time constant $(p<0.05)$ and an increase in mean input resistance $(p<0.005)$ occurred in MSNs obtained from YAC128 mice compared with WTs at 7 months. The mean capacitance also decreased, but this difference was not statistically significant ( $p=0.057)$. Increases in input resistance and decreases in capacitance and membrane time constants of MSNs have been observed in other mouse models of HD (Starling et al., 2005).

In cells from both WT and YAC128 mice, AMPA $(100 \mu \mathrm{M})$ application produced a rapid peak response that desensitized quickly (Fig. $8 \mathrm{~A}$ ). The amplitude of the AMPA peak increased markedly in the presence of CTZ $(10 \mu \mathrm{M})$, an inhibitor of AMPAR desensitization (Fig. $8 B$ ), with little difference in the qualitative appearance of the response between age groups (Fig. $8 A, B)$. At 1 month in response to AMPA or AMPA plus CTZ, cells from YAC128 mice displayed higher mean peak current $(p<0.02$ and $p<0.025$ for AMPA and AMPA plus CTZ, respectively) and mean peak current density $(p<0.005$ and $p<$ 0.006 for AMPA and AMPA plus CTZ, respectively) than cells from WT mice (Fig. $8 C 1, C 2, D 1, D 2)$. Mean steady-state currents and current densities were also higher in cells from YAC128 mice at 1 month of age, but the difference was significant for only the steady-state current densities $(p<0.05)$ (Fig. 8C3,D3). At 7 months, however, mean peak currents and peak current densities, as well as mean steady-state currents and steady-state current densities, were similar in cells from YAC128 and WT mice. Thus, although AMPAR-mediated responses in WTs generally increased with age, such responses in YAC128 cells declined.

\section{Contribution of $\mathrm{Ca}^{2+}$-permeable GluR2 subunits}

It is possible that the higher AMPAR-mediated currents observed at 1 month in YAC128 mice were the result of an increased proportion of GluR2-lacking $\mathrm{Ca}^{2+}$-permeable AMPARs. Philanthotoxin-433 (PhTX-433) is a polyamine toxin that selectively inhibits $\mathrm{Ca}^{2+}$ permeable AMPAR, which lack Q/R-edited GluR2 subunits (Tóth
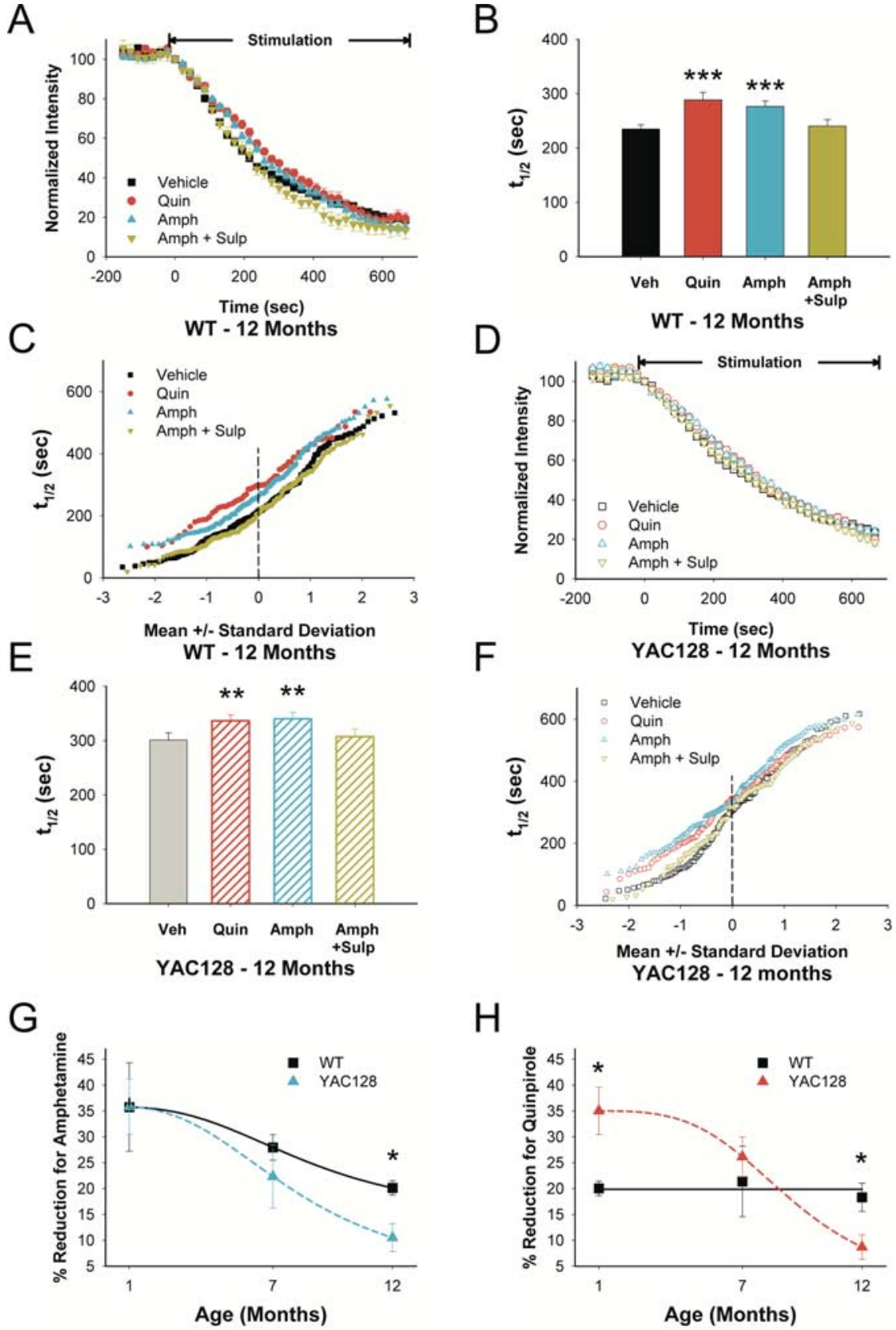

Figure 6. $\quad D_{2}$ receptor responses in 12-month-old YAC128 mice. $A$, In 12-month-old WTs, both quinpirole (Quin) and amphetamine (Amph) inhibited FM1-43 release. Sulpiride (Sulp) reversed the effect of Amph. $\boldsymbol{B}$, Distribution of mean $t_{1 / 2}$ of release for destaining curves shown in $\boldsymbol{A} . n=258,56,157$, and 127 puncta for vehicle (Veh), Quin, Amph, and Amph + Sulp, respectively. ${ }^{* * *} p<0.001$ compared with Veh, Mann-Whitney test. C, Individual terminal halftimes of release from averaged puncta shown in $\boldsymbol{A}$. D, In slices from 12-month-old YAC128 mice, both Quin and Amph inhibited FM1-43 release. Sulp reversed the modulating effect of Amph. $\boldsymbol{E}$, Distribution of mean $t_{1 / 2}$ of release for destaining curves shown in $\boldsymbol{D} . n=139,133,153$, and 96 puncta for Veh, Quin, Amph, and Amph + Sulp, respectively. ${ }^{* *} p<0.01$ compared with Veh, Mann-Whitney test. $\boldsymbol{F}$, Individual terminal halftimes of release from averaged puncta shown in $\boldsymbol{D}$. G, Percentage change in average corticostriatal terminal halftimes after Amph. $n=4$ mice per condition. ${ }^{*} p<0.05$, ANOVA. $\boldsymbol{H}$, Percentage change in average corticostriatal terminal halftimes after Quin. $n=$ 4 mice per condition. ${ }^{*} p<0.05$, ANOVA. Curves for $\boldsymbol{G}$ and $\boldsymbol{H}$ were fit with a Hill equation.

and McBain, 1998). We compared the contribution of $\mathrm{Ca}^{2+}$ permeable AMPARs by using PhTX-433 inhibition of AMPA plus CTZ-induced peak currents (Fig. 9A). At both ages and in both genotypes, $\sim 10-15 \%$ of the AMPA plus CTZ peak current was blocked by PhTX-433 $(10 \mu \mathrm{M})$. However, there were no differences in the mean percentage of the AMPA current blocked by PhTX-433 between YAC128 and WT cells at either 1 or 7 months. 
A
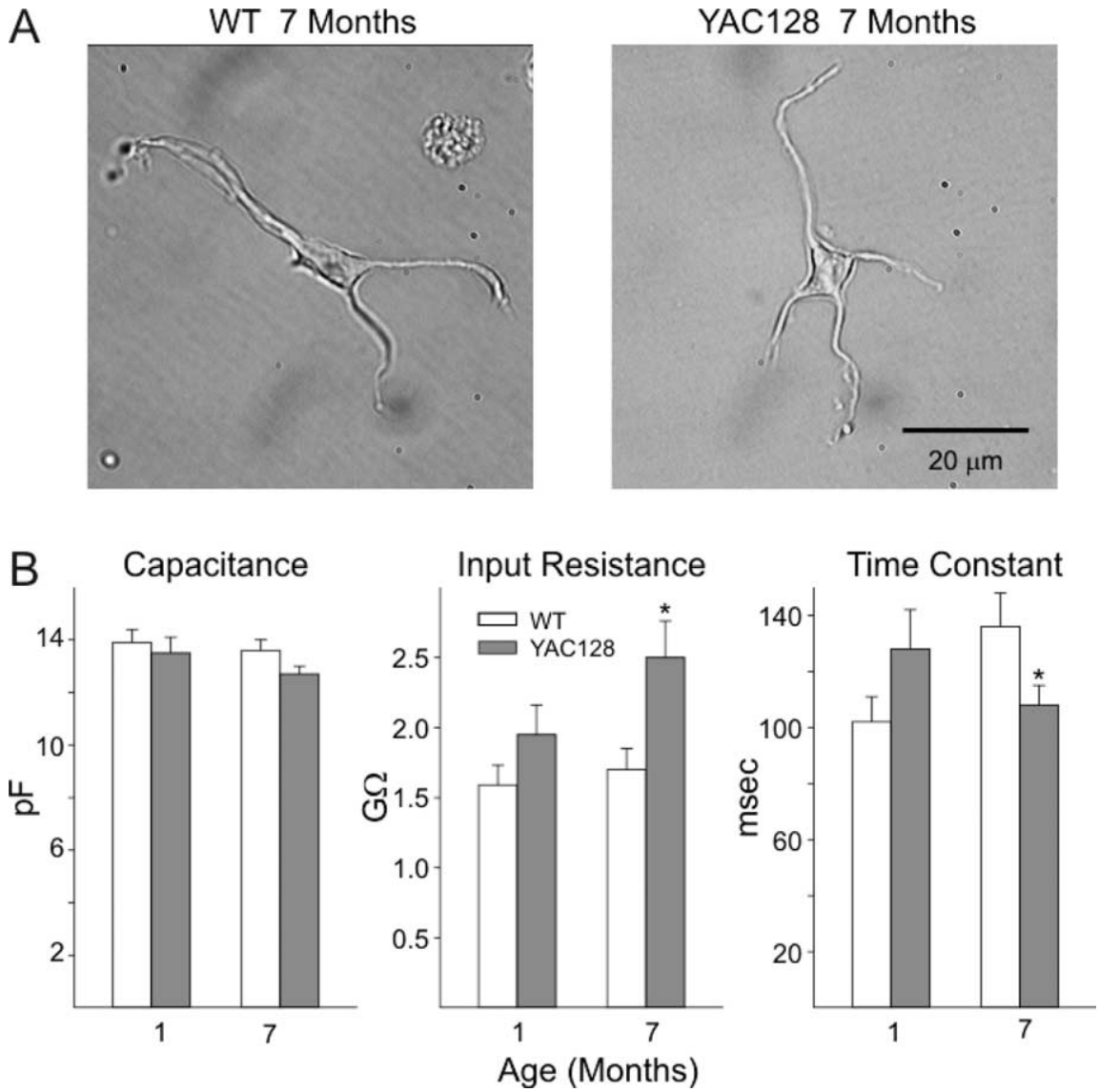

Figure 7. Membrane properties of acutely dissociated striatal MSNs. A shows representative images of MSNs from YAC128 mice and their WT littermates at 7 months. $\boldsymbol{B}$ shows bar graphs of mean \pm SE capacitance, input resistance, and time constants from cells from YAC128 mice at 1 and 7 months. Numbers of cells: 1 month YAC128 $=18, W T=26 ; 7$ month $Y A C 128=35, W T=$ 22. ${ }^{*} p<0.05,{ }^{* *} p<0.01,{ }^{* * *} p<0.005$.

\section{Desensitization of AMPAR-mediated responses in YAC128 mice}

In addition to its effects on peak AMPA currents, CTZ also differentially modulates AMPAR desensitization depending on the predominance of either the FLIP or the FLOP splice variants. The desensitization rates are slower when the FLIP version of AMPARs predominates and faster when the FLOP version predominates (Partin et al., 1994, 1995; Vorobjev et al., 2000). Striatal MSNs mainly express FLIP variants of GluR1, GluR2, and GluR3 AMPAR subunits (Vorobjev et al., 2000). As an index of the ratio of FLIP and FLOP variants in the composition of striatal AMPARs, we examined the ratio of AMPA plus CTZ current at peak and $1.5 \mathrm{~s}$ after the peak (at the halfway point of the $3 \mathrm{~s}$ exposure) to calculate the extent of the decay in peak current of these responses. The desensitization-induced decay in AMPA plus CTZ currents was significantly lower in YAC128 mice both at 1 month $(p=0.019)$ and 7 months $(p=0.012)$ (Fig. 9B). Thus, MSNs from YAC128 mice at both ages may express a higher proportion of FLIP variant compared with those of WTs. Moreover, the FLIP to FLOP ratio remained unchanged in both genotypes because the desensitization-induced decay in peak currents at 1 and 7 months were approximately the same.

\section{Concentration-response functions of AMPAR-mediated currents}

Finally, we determined whether age-dependent alterations in glutamate release produced sensitivity changes in AMPAR- mediated responses. Different concentrations of AMPA (1-1000 $\mu \mathrm{M})$ applied to a subset of neurons at 1 and 7 months from both YAC128 and WT mice produced similar sigmoid dose-response curves (Fig. 9C). The $\mathrm{EC}_{50}$ and Hill coefficients were similar at each age in cells from WT and YAC128 animals, suggesting that apparent affinity of the AMPA receptor for AMPA does not differ significantly.

\section{Discussion}

Glutamate receptor-mediated excitoxicity appears to be a major contributor to the pathophysiology of neurodegenerative illnesses, including HD (McDonald and Johnston, 1990; Lipton and Rosenberg, 1994). A considerable body of evidence derived from HD mouse models suggests that the mutation promotes abnormal synaptic function (Cepeda et al., 2003; Li et al., 2004; Smith et al., 2005; Milnerwood and Raymond, 2007). The present study combined electrophysiological recordings from striatal MSNs with optical measurements of release from corticostriatal terminals. The results indicate that alterations in corticostriatal synapses were biphasic and involved both presynaptic and postsynaptic components. Synaptic responses were increased in young, presymptomatic mice attributable to an enhancement in both glutamate release and postsynaptic AMPAR function. Development of the motor phenotype in YAC128 mice coincided with a decrease in synaptic responses that were attributable to combined presynaptic and postsynaptic effects. At 12 months, glutamate release, synaptic response amplitude, and their modulation by $\mathrm{D}_{2}$ receptors decreased markedly.

\section{Mutant huntingtin induces biphasic alterations in corticostriatal activity}

In 1-month-old YAC128 mice, enhanced AMPAR-mediated synaptic responses corresponded to an increased responsiveness of MSNs to cortical stimulation and to accelerated exocytosis from cortical terminals. This age-specific potentiation in excitability occurred in all cortical terminals and is consistent with the hypothesis that increased synaptic release of glutamate might induce excitotoxic injury in MSNs (DiFiglia, 1990; Calabresi et al., 1995). In contrast to our findings, in which we used extrastriatal stimulation, another study using intrastriatal evoked EPSCs showed that synaptic AMPAR currents recorded from MSNs in 1-month-old YAC128 mice were reduced when compared with those obtained from nonpathologic YAC18 mice (Milnerwood and Raymond, 2007). This discrepancy might be expected because intrastriatal electrical stimulation would likely release dopamine (Bamford et al., 2004b) and modulate the relative amplitudes of the AMPAR response.

In cells from YAC128 mice, there was a decrease in the size of the synaptically evoked response with age. In contrast, the size of the response increased in WT mice. This age-related effect led to a significant difference in response size when the comparisons 
were made at 7 months. At 12 months, the synaptic response amplitude in YAC128 MSNs remained depressed. Therefore, the observed differences in age-related excitability reflect changes in both transgenic and WT mice.

The optical results also demonstrated that corticostriatal release progressively declined in YAC128 mice. The accelerating deterioration of corticostriatal function in YAC128 mice was indicated by a decline in active corticostriatal terminals, accompanied by a decreased rate of exocytosis of the recycling synaptic vesicle pool or by a smaller pool of recycling synaptic vesicles. This reduction in glutamate release from cortical projections would diminish striatal excitation, which may provoke changes in postsynaptic receptor sensitivity as a compensatory mechanism and account for some of the motor abnormalities manifest in older $\mathrm{HD}$ mice. As previously hypothesized based on electrophysiological studies in R6/2 mice, the reduction in synaptic activity may lead to loss of synaptic contacts so that, when glutamate is released, it could act at extrasynaptic sites in which NMDA receptors containing NR2B subunits are enriched (Shehadeh et al., 2006; Cepeda et al., 2007). Activation of extrasynaptic NMDA receptors could then activate a proapoptotic pathway (Papadia and Hardingham, 2007; Léveillé et al., 2008), leading to an additional loss of MSNs. The progressive disconnection between the cortex and striatum and the consequential reduction of regulated glutamate release could also diminish the release of neurotrophic factors such as brain-derived neurotrophic factor (Cepeda et al., 2003) that might produce a progressive loss in the dendritic spines of MSNs (Cepeda et al., 2007).

\section{Alterations in MSN membrane properties and AMPAR responses}

Similar to published results in R6/2 mice (Cepeda et al., 2001; Klapstein et al., 2001; Starling et al., 2005), recordings in MSNs from YAC128 mice demonstrated decreased cellular capacitance and time constant with the development of the phenotype, although input resistance increased. We have interpreted these findings to indicate that the declines in capacitance and time constants are attributable to decreases in neuronal size and the extent of the dendritic field, whereas the increase in input resistance is attributable to a loss of inwardly rectifying $\mathrm{K}^{+}$channels (Ariano et al., 2002, 2005). Thus, it appears that changes in MSN membrane properties represent a robust alteration that is produced by the mutation.
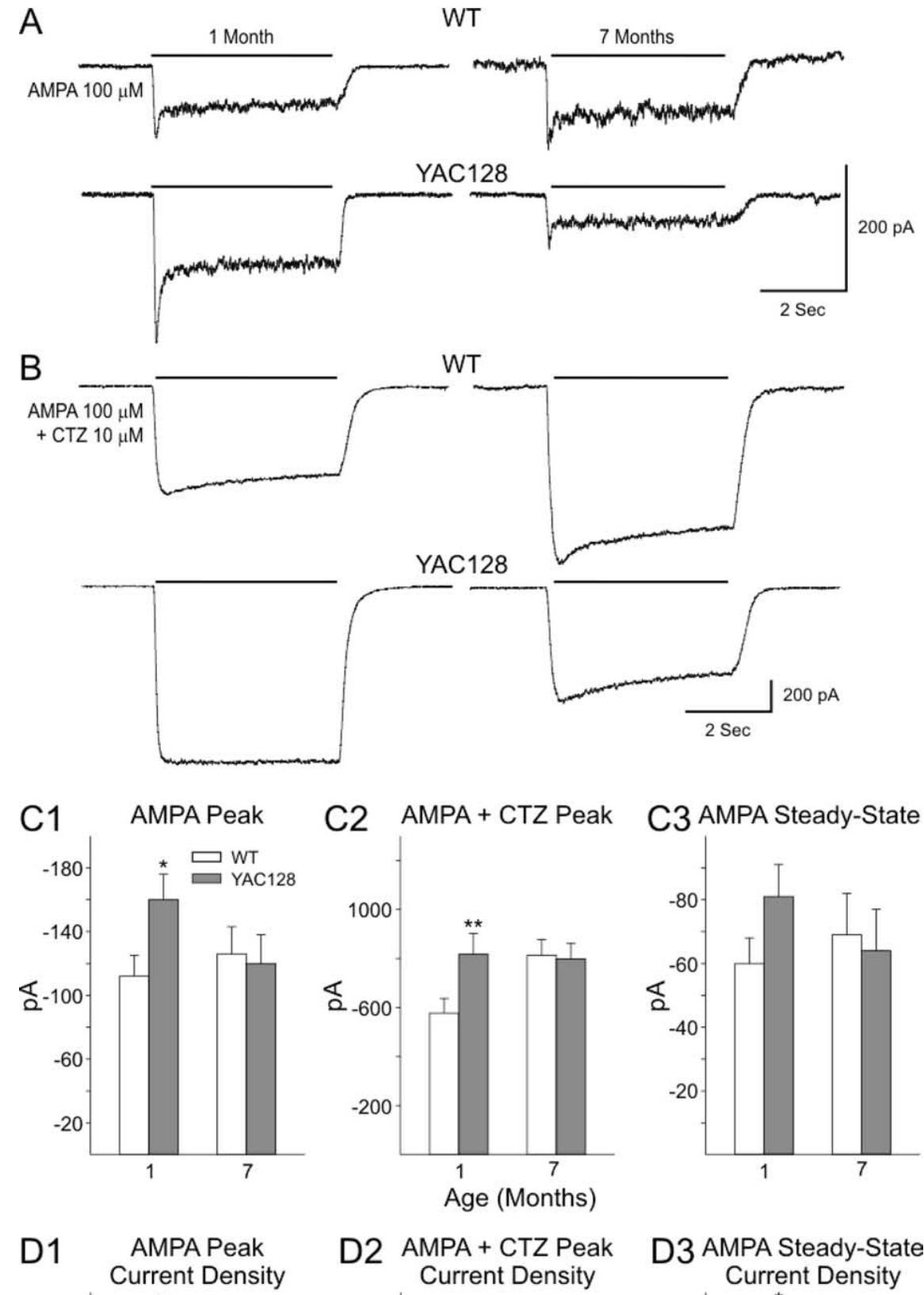

D2 AMPA + CTZ Peak
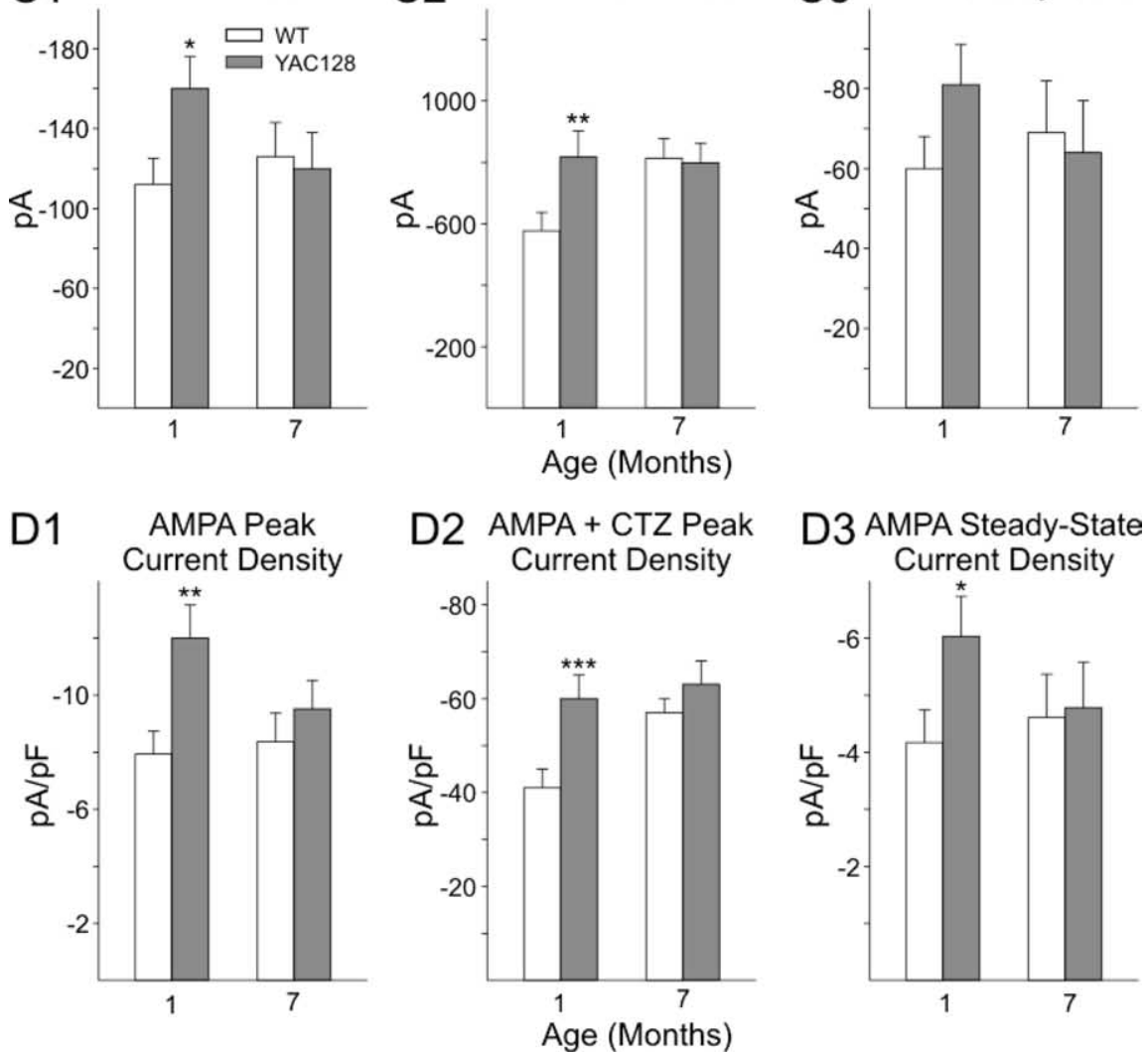

Figure 8. AMPA currents in acutely dissociated MSNs from YAC128 and WT mice. $A, B$, Representative traces showing inward currents evoked by $100 \mu \mathrm{M}$ AMPA, either alone or in the presence of $10 \mu \mathrm{M}$ CTZ, from MSNs from YAC128 and WT mice at 1 and 7 months. Note higher peak AMPA and AMPA plus CTZ currents at 1 month and AMPA steady-state currents at 1 month in YAC128 mice. C, Bar graphs illustrating mean \pm SE peak AMPA currents (C1), mean peak AMPA plus CTZ currents (C2), and mean AMPA steady-state currents (C3) at each age. D, Bar graphs illustrating mean \pm SE peak AMPA current densities (D1), mean peak AMPA plus CTZ current densities (D2), and mean AMPA steady-state current densities (D3) at each age. Numbers of cells in each group are the same as in Figure 7. ${ }^{*} p<0.05,{ }^{* *} p<0.01,{ }^{* * *} p<0.005$. 


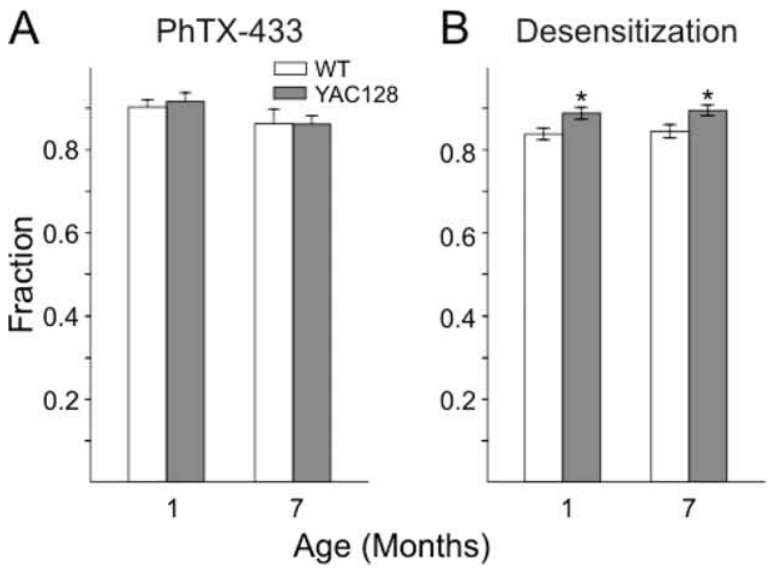

C

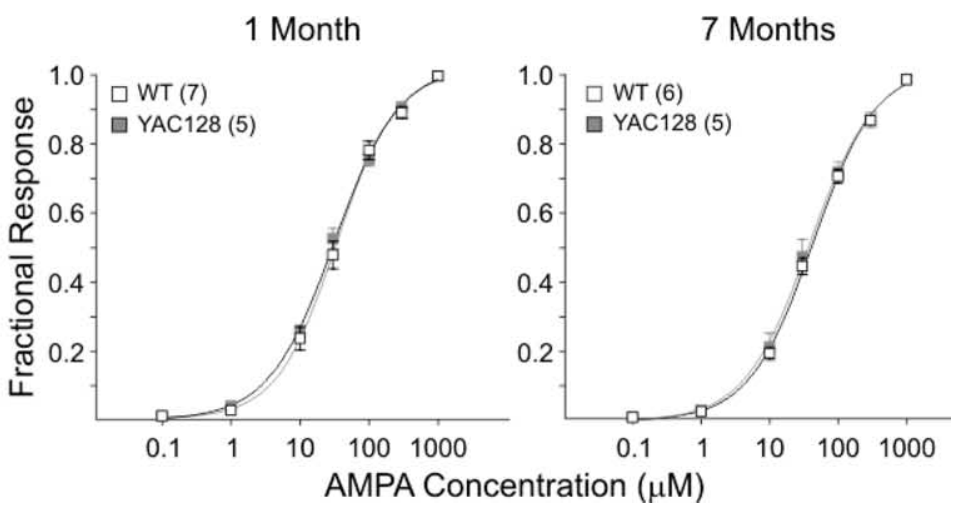

Figure 9. Effects of PhTX-433 and desensitization of AMPAR responses and concentration-response functions in striatal MSNs. A, Bar graphs showing mean \pm SE fractional AMPA plus CTZ peak currents after inhibition by $10 \mu \mathrm{m}$ PhTX-433 in acutely dissociated MSNs from YAC128 mice at each age tested. Fractional peak currents in MSNs from YAC128 mice and their WT littermates were similar at each age. $\boldsymbol{B}$, Bar graphs showing mean \pm SE fractional AMPA plus CTZ currents at $1.5 \mathrm{~s}$ after the peak in acutely dissociated MSNs from YAC128 mice and their WT littermates at each age tested. A higher mean fractional current occurred in YAC128 mice at both 1 and 7 months. Numbers of cells: 1 month YAC128 $=18, W T=16 ; 7$ month YAC128 $=11$, WT $=11 .{ }^{*} p<0.05$. $C$, Concentration-response functions to application of an increasing series of AMPA concentrations (0.1-1000 $\mu \mathrm{m})$ in the continuous presence of $10 \mu \mathrm{m}$ CTZ. Peak currents were recorded at each concentration, and points were fitted to concentration-response functions. $\mathrm{EC}_{50}$ values and Hill coefficients were similar in YAC128 cells and those from their respective WT littermates at all ages examined. Numbers of cells for each group are in parentheses.

In isolated MSNs from YAC128 mice at 1 month, both peak and steady-state AMPAR currents were increased. At 7 months, when the phenotype is well developed, there were no differences in responses evoked by application of AMPA. At both ages, the concentration-response functions were similar in YAC128 and WT mice, suggesting that the increased AMPAR responsiveness in young mice was not attributable to changes in receptor affinity. AMPAR desensitization in YAC128 cells was reduced at both ages, possibly indicating differential subunit composition (André et al., 2006). However, AMPAR-mediated responses at both ages were not significantly blocked by PhTX-433, nor were there differences in PhTX-433 block between transgenic and WT mice, indicating that $\mathrm{Ca}^{2+}$-permeable AMPARs were not contributing greatly to the enhanced AMPAR responses observed in presymptomatic YAC128 mice.

Terminal subpopulations and pathway-specific degeneration An advantage of presynaptic optical measurements is that variability between individual presynaptic terminals can be analyzed. Young YAC128 mice demonstrated enhanced exocytosis from terminals with a high probability of release. At 7 months, augmented exocytosis persisted in fast-releasing terminals but slower-releasing terminals became inhibited. At 12 months, the YAC128 mutation produced additional inhibition at all terminals. It is possible that these temporal changes in terminal subpopulations might affect specific types of striatal MSNs. Although HD produces deleterious effects in all MSNs, there is an earlier effect on $\mathrm{D}_{2}$ receptor and enkephalin-positive cells that form the indirect striatal output projection to the external globus pallidus (Reiner et al., 1988). MSNs that express $D_{1}$ receptors and substance $\mathrm{P}$ are less prone to injury. These neurons project to the substantia nigra and form the direct striatal output pathway (Albin et al., 1989; Richfield et al., 1995; Sapp et al., 1995). $\mathrm{D}_{2}$-positive cells display more spontaneous inward synaptic currents and larger-amplitude events than $\mathrm{D}_{1}$-positive MSNs (Cepeda et al., 2007, 2008). This suggests that $D_{2}$-positive MSNs receive a larger synaptic input (Lei et al., 2004) and may be more susceptible to selective degeneration. Because the faster-releasing terminals would induce larger-amplitude postsynaptic currents
(Bamford et al., 2004b) in $\mathrm{D}_{2}$-presenting MSNs (Kreitzer and Malenka, 2007), persistence of these amplified responses into adulthood would provoke excitatory stress on $\mathrm{D}_{2}$-positive neurons with preferential degeneration of MSNs projecting to the globus pallidus (Reiner et al., 1988; Albin et al., 1990).

\section{Biphasic alterations in $\mathrm{D}_{2}$ dopamine receptor filtering}

The distribution of individual terminal halftimes in WT mice demonstrated that $\mathrm{D}_{2}$ receptor stimulation depressed exocytosis from the majority of cortical terminals, preferentially inhibiting the activity of the terminals with the lowest probability of release. This effect occurs in the dynamic and kinetic range of dopamine input associated with either salient behavioral stimuli or psychostimulants (Bamford et al., 2004b). Thus, dopamine release associated with salience during motor learning would reinforce specific corticostriatal connections by filtering out less effective cortical terminal inputs (Bamford et al., 2004b; Dani and Zhou, 2004). The results suggest that the YAC128 mutation alters $D_{2}$ receptor-dependent filtering. In WT mice, the inhibitory effect of the $\mathrm{D}_{2}$ receptor agonist quinpirole on glutamate release remained stable, whereas the filtering effect of amphetamine decreased with age. Therefore, the number or sensitivity of presynaptic $\mathrm{D}_{2}$ receptors on glutamatergic terminals may remain stable, whereas the releasing effect of amphetamine diminishes in senescence (Gerhardt and Maloney, 1999). In YAC128 mice, quinpirole provoked a marked increase in corticostriatal inhibition at 1 month but was much less effective than WTs at 12 months. Corticostriatal inhibition by amphetamine in YAC128 mice also declined with age but to a much greater degree than WT. These $\mathrm{D}_{2}$ receptor responses might occur through alterations in receptor translation or by an increase in receptor affinity attributable to an early reduction in dopamine availability (Ariano et al., 2002; Johnson et al., 2006, 2007), followed by tonic corticostriatal inhibition produced by progressive neuro-axonal dysfunction (Klapstein et al., 2001; Laforet et al., 2001). Although a loss of dopamine receptor proteins has been demonstrated in R6/2 and other HD mouse models (Suzuki et al., 2001; Ariano et al., 2002; Heng et al., 2007), dopamine receptor density is unchanged in 12-month-old YAC128 mice (Benn et al., 2007). This may represent a compen- 
satory mechanism for decreased dopamine availability because the number of striatal neurons is reduced by $15 \%$ in this age group (Slow et al., 2003). Together, these age-dependent alterations in dopamine receptors and dopamine availability are also likely associated with the motoric deficits found in YAC128 animals.

\section{Conclusions}

The biphasic age-dependent alterations along the corticostriatal pathway in YAC128 mice emphasize the complexity of the neuronal effects produced by mutant huntingtin. There are age- and disease-dependent alterations in both corticostriatal terminal subpopulations and alterations in AMPA and dopamine receptor function that will produce asymmetrical degenerative changes to specific subpopulations of striatal cells. Such changes emphasize the importance of designing therapies that separately target different phases of the disease. The present findings suggest that glutamate receptor antagonists may only be beneficial if started in the presymptomatic stage, whereas later therapies should be aimed at increasing synaptic activity. Future investigations should examine how the manipulation of other neurotransmitters that modulate corticostriatal activity might reverse these alterations.

\section{References}

Albin RL, Young AB, Penney JB (1989) The functional anatomy of basal ganglia disorders. Trends Neurosci 12:366-375.

Albin RL, Reiner A, Anderson KD, Penney JB, Young AB (1990) Striatal and nigral neuron subpopulations in rigid Huntington's disease: implications for the functional anatomy of chorea and rigidity-akinesia. Ann Neurol 27:357-365.

André VM, Cepeda C, Venegas A, Gomez Y, Levine MS (2006) Altered cortical glutamate receptor function in the R6/2 model of Huntington's disease. J Neurophysiol 95:2108-2119.

Ariano MA, Aronin N, Difiglia M, Tagle DA, Sibley DR, Leavitt BR, Hayden MR, Levine MS (2002) Striatal neurochemical changes in transgenic models of Huntington's disease. J Neurosci Res 68:716-729.

Ariano MA, Cepeda C, Calvert CR, Flores-Hernández J, HernándezEcheagaray E, Klapstein GJ, Chandler SH, Aronin N, DiFiglia M, Levine MS (2005) Striatal potassium channel dysfunction in Huntington's disease transgenic mice. J Neurophysiol 93:2565-2574.

Bamford NS, Robinson S, Palmiter RD, Joyce JA, Moore C, Meshul CK (2004a) Dopamine modulates release from corticostriatal terminals. J Neurosci 24:9541-9552.

Bamford NS, Zhang H, Schmitz Y, Wu NP, Cepeda C, Levine MS, Schmauss C, Zakharenko SS, Zablow L, Sulzer D (2004b) Heterosynaptic dopamine neurotransmission selects sets of corticostriatal terminals. Neuron 42:653-663.

Bamford NS, Zhang H, Joyce JA, Scarlis CA, Hanan W, Wu NP, André VM, Cohen R, Cepeda C, Levine MS, Harleton E, Sulzer D (2008) Repeated exposure to methamphetamine causes long-lasting presynaptic corticostriatal depression that is renormalized with drug readministration. Neuron 58:89-103.

Bargas J, Howe A, Eberwine J, Cao Y, Surmeier DJ (1994) Cellular and molecular characterization of $\mathrm{Ca}^{2+}$ currents in acutely isolated, adult rat neostriatal neurons. J Neurosci 14:6667-6686.

Benn CL, Slow EJ, Farrell LA, Graham R, Deng Y, Hayden MR, Cha JH (2007) Glutamate receptor abnormalities in the YAC128 transgenic mouse model of Huntington's disease. Neuroscience 147:354-372.

Betz WJ, Bewick GS (1992) Optical analysis of synaptic vesicle recycling at the frog neuromuscular junction. Science 255:200-203.

Calabresi P, De Murtas M, Pisani A, Stefani A, Sancesario G, Mercuri NB, Bernardi G (1995) Vulnerability of medium spiny striatal neurons to glutamate: role of $\mathrm{Na}^{+} / \mathrm{K}^{+}$ATPase. Eur J Neurosci 7:1674-1683.

Cepeda C, Colwell CS, Itri JN, Chandler SH, Levine MS (1998) Dopaminergic modulation of NMDA-induced whole cell currents in neostriatal neurons in slices: contribution of calcium conductances. J Neurophysiol 79:82-94.

Cepeda C, Ariano MA, Calvert CR, Flores-Hernández J, Chandler SH, Leavitt
BR, Hayden MR, Levine MS (2001) NMDA receptor function in mouse models of Huntington disease. J Neurosci Res 66:525-539.

Cepeda C, Hurst RS, Calvert CR, Hernández-Echeagaray E, Nguyen OK, Jocoy E, Christian LJ, Ariano MA, Levine MS (2003) Transient and progressive electrophysiological alterations in the corticostriatal pathway in a mouse model of Huntington's disease. J Neurosci 23:961-969.

Cepeda C, Wu N, André VM, Cummings DM, Levine MS (2007) The corticostriatal pathway in Huntington's disease. Prog Neurobiol 81:253-271.

Cepeda C, André VM, Yamazaki I, Wu N, Kleiman-Weiner M, Levine MS (2008) Differential electrophysiological properties of dopamine D1 and D2 receptor-containing striatal medium-sized spiny neurons. Eur J Neurosci 27:671-682.

Dani JA, Zhou FM (2004) Selective dopamine filter of glutamate striatal afferents. Neuron 42:522-524.

DiFiglia M (1990) Excitotoxic injury of the neostriatum: a model for Huntington's disease. Trends Neurosci 13:286-289.

Gerhardt GA, Maloney RE Jr (1999) Microdialysis studies of basal levels and stimulus-evoked overflow of dopamine and metabolites in the striatum of young and aged Fischer 344 rats. Brain Res 816:68-77.

Hebert MA, Gerhardt GA (1999) Age-related changes in the capacity, rate, and modulation of dopamine uptake within the striatum and nucleus accumbens of Fischer 344 rats: an in vivo electrochemical study. J Pharmacol Exp Ther 288:879-887.

Heng MY, Tallaksen-Greene SJ, Detloff PJ, Albin RL (2007) Longitudinal evaluation of the Hdh(CAG) 150 knock-in murine model of Huntington's disease. J Neurosci 27:8989-8998.

Huntington's Disease Collaborative Research Group (1993) A novel gene containing a trinucleotide repeat that is expanded and unstable on Huntington's disease chromosomes. Cell 72:971-983.

Isaacson JS, Hille B (1997) GABA(B)-mediated presynaptic inhibition of excitatory transmission and synaptic vesicle dynamics in cultured hippocampal neurons. Neuron 18:143-152.

Johnson MA, Rajan V, Miller CE, Wightman RM (2006) Dopamine release is severely compromised in the R6/2 mouse model of Huntington's disease. J Neurochem 97:737-746.

Johnson MA, Villanueva M, Haynes CL, Seipel AT, Buhler LA, Wightman RM (2007) Catecholamine exocytosis is diminished in R6/2 Huntington's disease model mice. J Neurochem 103:2102-2110.

Kay AR, Alfonso A, Alford S, Cline HT, Holgado AM, Sakmann B, Snitsarev VA, Stricker TP, Takahashi M, Wu LG (1999) Imaging synaptic activity in intact brain and slices with FM1-43 in C. elegans, lamprey, and rat. Neuron 24:809-817.

Klapstein GJ, Fisher RS, Zanjani H, Cepeda C, Jokel ES, Chesselet MF, Levine MS (2001) Electrophysiological and morphological changes in striatal spiny neurons in R6/2 Huntington's disease transgenic mice. J Neurophysiol 86:2667-2677.

Kreitzer AC, Malenka RC (2007) Endocannabinoid-mediated rescue of striatal LTD and motor deficits in Parkinson's disease models. Nature 445:643-647.

Laforet GA, Sapp E, Chase K, McIntyre C, Boyce FM, Campbell M, Cadigan BA, Warzecki L, Tagle DA, Reddy PH, Cepeda C, Calvert CR, Jokel ES, Klapstein GJ, Ariano MA, Levine MS, DiFiglia M, Aronin N (2001) Changes in cortical and striatal neurons predict behavioral and electrophysiological abnormalities in a transgenic murine model of Huntington's disease. J Neurosci 21:9112-9123.

Lei W, Jiao Y, Del Mar N, Reiner A (2004) Evidence for differential cortical input to direct pathway versus indirect pathway striatal projection neurons in rats. J Neurosci 24:8289-8299.

Léveillé F, El Gaamouch F, Gouix E, Lecocq M, Lobner D, Nicole O, Buisson A (2008) Neuronal viability is controlled by a functional relation between synaptic and extrasynaptic NMDA receptors. FASEB J 22:4258-4271.

Levine MS, Klapstein GJ, Koppel A, Gruen E, Cepeda C, Vargas ME, Jokel ES, Carpenter EM, Zanjani H, Hurst RS, Efstratiadis A, Zeitlin S, Chesselet MF (1999) Enhanced sensitivity to $N$-methyl-D-aspartate receptor activation in transgenic and knockin mouse models of Huntington's disease. J Neurosci Res 58:515-532.

Li H, Wyman T, Yu ZX, Li SH, Li XJ (2003a) Abnormal association of mutant huntingtin with synaptic vesicles inhibits glutamate release. Hum Mol Genet 12:2021-2030.

Li JY, Plomann M, Brundin P (2003b) Huntington's disease: a synaptopathy? Trends Mol Med 9:414-420. 
Li L, Murphy TH, Hayden MR, Raymond LA (2004) Enhanced striatal NR2B-containing $N$-methyl-D-aspartate receptor-mediated synaptic currents in a mouse model of Huntington disease. J Neurophysiol 92:2738-2746.

Lipton SA, Rosenberg PA (1994) Excitatory amino acids as a final common pathway for neurologic disorders. N Engl J Med 330:613-622.

Mainen ZF, Sejnowski TJ (1996) Influence of dendritic structure on firing pattern in model neocortical neurons. Nature 382:363-366.

Mainen ZF, Maletic-Savatic M, Shi SH, Hayashi Y, Malinow R, Svoboda K (1999) Two-photon imaging in living brain slices. Methods 18:231-239, 181.

Mangiarini L, Sathasivam K, Seller M, Cozens B, Harper A, Hetherington C, Lawton M, Trottier Y, Lehrach H, Davies SW, Bates GP (1996) Exon 1 of the HD gene with an expanded CAG repeat is sufficient to cause a progressive neurological phenotype in transgenic mice. Cell 87:493-506.

McDonald JW, Johnston MV (1990) Physiological and pathophysiological roles of excitatory amino acids during central nervous system development. Brain Res Brain Res Rev 15:41-70.

Milnerwood AJ, Raymond LA (2007) Corticostriatal synaptic function in mouse models of Huntington's disease: early effects of huntingtin repeat length and protein load. J Physiol 585:817-831.

Papadia S, Hardingham GE (2007) The dichotomy of NMDA receptor signaling. Neuroscientist 13:572-579.

Partin KM, Patneau DK, Mayer ML (1994) Cyclothiazide differentially modulates desensitization of alpha-amino-3-hydroxy-5-methyl-4isoxazolepropionic acid receptor splice variants. Mol Pharmacol 46:129-138.

Partin KM, Bowie D, Mayer ML (1995) Structural determinants of allosteric regulation in alternatively spliced AMPA receptors. Neuron 14:833-843.

Reiner A, Albin RL, Anderson KD, D'Amato CJ, Penney JB, Young AB (1988) Differential loss of striatal projection neurons in Huntington disease. Proc Natl Acad Sci U S A 85:5733-5737.

Richfield EK, Maguire-Zeiss KA, Cox C, Gilmore J, Voorn P (1995) Reduced expression of preproenkephalin in striatal neurons from Huntington's disease patients. Ann Neurol 37:335-343.

Robinson DL, Phillips PE, Budygin EA, Trafton BJ, Garris PA, Wightman RM (2001) Sub-second changes in accumbal dopamine during sexual behavior in male rats. Neuroreport 12:2549-2552.

Ryan TA, Reuter H, Wendland B, Schweizer FE, Tsien RW, Smith SJ (1993) The kinetics of synaptic vesicle recycling measured at single presynaptic boutons. Neuron 11:713-724.

Sapp E, Ge P, Aizawa H, Bird E, Penney J, Young AB, Vonsattel JP, DiFiglia M (1995) Evidence for a preferential loss of enkephalin immunoreactivity in the external globus pallidus in low grade Huntington's disease using high resolution image analysis. Neuroscience 64:397-404.

Sapp E, Penney J, Young A, Aronin N, Vonsattel JP, DiFiglia M (1999) Axonal transport of $\mathrm{N}$-terminal huntingtin suggests early pathology of corticostriatal projections in Huntington disease. J Neuropathol Exp Neurol 58:165-173.

Schmitz Y, Lee CJ, Schmauss C, Gonon F, Sulzer D (2001) Amphetamine distorts stimulation-dependent dopamine overflow: effects on $\mathrm{D}_{2}$ auto- receptors, transporters, and synaptic vesicle stores. J Neurosci 21:5916-5924.

Shehadeh J, Fernandes HB, Zeron Mullins MM, Graham RK, Leavitt BR, Hayden MR, Raymond LA (2006) Striatal neuronal apoptosis is preferentially enhanced by NMDA receptor activation in YAC transgenic mouse model of Huntington disease. Neurobiol Dis 21:392-403.

Slow EJ, van Raamsdonk J, Rogers D, Coleman SH, Graham RK, Deng Y, Oh R, Bissada N, Hossain SM, Yang YZ, Li XJ, Simpson EM, Gutekunst CA, Leavitt BR, Hayden MR (2003) Selective striatal neuronal loss in a YAC128 mouse model of Huntington disease. Hum Mol Genet 12:1555-1567.

Smith R, Brundin P, Li JY (2005) Synaptic dysfunction in Huntington's disease: a new perspective. Cell Mol Life Sci 62:1901-1912.

Starling AJ, André VM, Cepeda C, de Lima M, Chandler SH, Levine MS (2005) Alterations in $\mathrm{N}$-methyl-D-aspartate receptor sensitivity and magnesium blockade occur early in development in the R6/2 mouse model of Huntington's disease. J Neurosci Res 82:377-386.

Stern EA, Kincaid AE, Wilson CJ (1997) Spontaneous subthreshold membrane potential fluctuations and action potential variability of rat corticostriatal and striatal neurons in vivo. J Neurophysiol 77:1697-1715.

Stevens CF, Tsujimoto T (1995) Estimates for the pool size of releasable quanta at a single central synapse and for the time required to refill the pool. Proc Natl Acad Sci U S A 92:846-849.

Suzuki M, Desmond TJ, Albin RL, Frey KA (2001) Vesicular neurotransmitter transporters in Huntington's disease: initial observations and comparison with traditional synaptic markers. Synapse 41:329-336.

Tóth K, McBain CJ (1998) Afferent-specific innervation of two distinct AMPA receptor subtypes on single hippocampal interneurons. Nat Neurosci 1:572-578.

Turmaine M, Raza A, Mahal A, Mangiarini L, Bates GP, Davies SW (2000) Nonapoptotic neurodegeneration in a transgenic mouse model of Huntington's disease. Proc Natl Acad Sci U S A 97:8093-8097.

Van Raamsdonk JM, Pearson J, Slow EJ, Hossain SM, Leavitt BR, Hayden MR (2005) Cognitive dysfunction precedes neuropathology and motor abnormalities in the YAC128 mouse model of Huntington's disease. J Neurosci 25:4169-4180.

Vonsattel JP, DiFiglia M (1998) Huntington disease. J Neuropathol Exp Neurol 57:369-384.

Vorobjev VS, Sharonova IN, Haas HL, Sergeeva OA (2000) Differential modulation of AMPA receptors by cyclothiazide in two types of striatal neurons. Eur J Neurosci 12:2871-2880.

Wölfel M, Schneggenburger R (2003) Presynaptic capacitance measurements and $\mathrm{Ca}^{2+}$ uncaging reveal submillisecond exocytosis kinetics and characterize the $\mathrm{Ca}^{2+}$ sensitivity of vesicle pool depletion at a fast CNS synapse. J Neurosci 23:7059-7068.

Young AB (2003) Huntingtin in health and disease. J Clin Invest 111:299-302.

Zakharenko SS, Zablow L, Siegelbaum SA (2001) Visualization of changes in presynaptic function during long-term synaptic plasticity. Nat Neurosci 4:711-717. 